\title{
Transversely isotropic poroelastic behaviour of the Callovo-Oxfordian claystone: A set of stress-dependent parameters
}

\author{
Philipp Braun · Siavash Ghabezloo • Pierre Delage · Jean \\ Sulem • Nathalie Conil
}

Accepted: 5 October 2020

\begin{abstract}
In the framework of a deep geological radioactive waste disposal in France, the hydromechanical properties of the designated host rock, the Callovo-Oxfordian claystone (COx), are investigated in laboratory tests. Experiments presented in this study are carried out to determine several coefficients required within a transversely isotropic material model. They include isotropic compression tests, pore pressure tests, and deviatoric loading tests parallel and perpendicular to the bedding plane. We emphasize the adapted experimental devices and testing procedures, necessary to detect small strains under high pressures, on a material, which is sensitive to water and has a very low permeability. In particular, we discovered a significant decrease of elastic stiffness with decreasing effective stress, which was observed to be reversible. In both isotropic and deviatoric tests, a notable anisotropic strain response was found. The Young modulus parallel to bedding was about 1.8 times higher than the one perpendicular to the bedding plane. A notably low Poisson ratio perpendicular to the bedding plane with values between 0.1 and 0.2 was evidenced. While the anisotropy of the back-calculated Biot coefficient was found to be low, a significant anisotropy of the Skempton coefficient was computed. The performed experiments provide an overdetermined set of material parameters at different stress levels. Using all determined parameters in a least square error regression scheme, seven independent elastic coefficients and their effective stress dependency are characterized. Parameters measured under isotropic loading are well represented by this set of coefficients, while the poroelastic framework with isotropic stress dependency is not sufficient to describe laboratory findings from triaxial loading.
\end{abstract}

Keywords Claystone · Transverse isotropy · Triaxial testing $\cdot$ Stress dependency $\cdot$ Poroelasticity

P. Braun · S. Ghabezloo · P. Delage · J. Sulem

Laboratoire Navier, 6-8 avenue Blaise-Pascal, Cité Descartes 77455 Champs-sur-Marne, Paris, France, philipp.braun@enpc.fr

N. Conil

Andra, Meuse/Haute-Marne Underground Research Laboratory, Bure, France 


\section{List of Symbols}

Note that the matrix notation is used throughout this work.

$\varepsilon_{i} \quad$ Strain vector containing the six independent components of the second rank strain tensor

$M_{i j} \quad$ Drained stiffness tensor in matrix format

$C_{i j} \quad$ Drained compliance tensor in matrix format

$\sigma_{i} \quad$ Stress vector containing the six independent components of the second rank stress tensor

$b_{i} \quad$ Biot's coefficient for $i$-th direction

$p_{f} \quad$ Pore fluid pressure

$E_{i} \quad$ Drained Young's modulus in the $i$-th direction

$\nu_{z h} \quad$ Drained Poisson's ratio perpendicular to bedding

$\nu_{z h}^{\prime} \quad$ Apparent drained Poisson's ratio under loading parallel to bedding

$\nu_{h h} \quad$ Drained Poisson's ratio parallel to bedding

$G \quad$ Shear modulus perpendicular to bedding

$G^{\prime} \quad$ Shear modulus parallel to bedding

$\phi_{0} \quad$ Porosity

$M \quad$ Biot's undrained modulus $M$

$N \quad$ Biot's skeleton modulus $N$

$K_{f} \quad$ Bulk modulus of the pore fluid

$K_{\phi} \quad$ Unjacketed pore modulus

$B_{i} \quad$ Skempton's coefficient for $i$-th direction

$K_{s} \quad$ Unjacketed bulk modulus

$M_{i j}^{u} \quad$ Undrained stiffness tensor in matrix format

$C_{i j}^{u} \quad$ Undrained compliance tensor in matrix format

$E_{u, i} \quad$ Undrained Young's modulus in the $i$-th direction

$\nu_{u, z h}$ Undrained Poisson's ratio perpendicular to bedding

$\nu_{u, h h}$ Undrained Poisson's ratio parallel to bedding

$\sigma^{\prime} \quad$ Terzaghi isotropic effective stress

$\sigma \quad$ Isotropic total stress

$\varepsilon_{v} \quad$ Volumetric strain

$K_{d} \quad$ Isotropic drained bulk modulus

$H \quad$ Biot's pore pressure loading modulus

$b \quad$ Isotropic Biot's coefficient

$V \quad$ Specimen volume

$m_{f} \quad$ Pore fluid mass

$K_{u} \quad$ Isotropic undrained bulk modulus

$B \quad$ Isotropic Skempton's coefficient

$D_{i} \quad$ Drained isotropic compression modulus in the $i$ th direction

$U_{i} \quad$ Undrained isotropic compression modulus in the $i$-th direction

$H_{i} \quad$ Biot's pore pressure loading modulus in the $i$-th direction

$R_{D} \quad$ Anisotropy ratio in drained isotropic compression

$R_{U} \quad$ Anisotropy ratio in undrained isotropic compression

$R_{H} \quad$ Anisotropy ratio in pore pressure loading

$R_{E} \quad$ Anisotropy ratio of drained Young's moduli $q \quad$ Deviatoric stress

$E_{z}^{\infty}, E_{z}^{0}, \beta$ Model parameters for regression analysis

$\rho \quad$ Wet density

$\rho_{d} \quad$ Dry density

$w \quad$ Water content

$S_{r} \quad$ Saturation degree

$s \quad$ Suction

$S \quad$ Standard deviation of the estimate

\section{Introduction}

The French National Agency for Nuclear Waste Management, Andra, is investigating the possibility of constructing a deep geological nuclear waste disposal facility in the Callovo-Oxfordian ( $\mathrm{COx}$ ) claystone, located in the east of France.

To study the host material and demonstrate the feasibility of the project, Andra constructed an underground research laboratory (URL) at $490 \mathrm{~m}$ depth, where the claystone has an average porosity of $17.5 \%$ and an average water content of $7.9 \%$ (Conil et al. 2018). An average clay content around $42 \%$ was mentioned by the same authors. Wileveau et al. (2007) determined a vertical and a minor horizontal total stress close to $12 \mathrm{MPa}$, a major horizontal stress close to 16 $\mathrm{MPa}$ and a pore pressure of 4.9 $\mathrm{MPa}$.

During extensive laboratory studies on its hydromechanical behaviour, the COx claystone was found transversely isotropic with larger stiffness parallel to the bedding plane (Chiarelli, 2000, Escoffier, 2002, Andra, 2005, Mohajerani et al., 2012, Zhang et al., 2012, Belmokhtar et al. 2017b). This feature, revealed also in many other types of shales, can be attributed to the sedimentary history of the material. Due to this fact, transversely isotropic poroelasticity was chosen as a framework for hydromechanical modelling purposes. A larger number of experiments is therefore necessary, compared to an isotropic material, to capture the complete material behaviour (e.g. two triaxial tests have to be carried out to determine the Young moduli and Poisson ratios both perpendicular and parallel to the bedding plane). While there are extensive data on the Young moduli perpendicular to bedding, provided by the aforementioned authors, fewer data are given on the Young modulus parallel to bedding and the Poisson ratios of saturated COx (Menaceur et al. 2015. Belmokhtar et al. 2018). Several experiments for establishing a set of poroelastic parameters were carried out in the present work. This includes triaxial compression parallel and perpendicular to the bedding plane in drained and undrained conditions, isotropic compression tests in both drained and undrained conditions, 
and pore pressure loading tests under constant total stress. The anisotropic strain response was measured in all experiments.

The COx claystone can be considered as a swelling claystone (Schmitt et al. 1994). In its natural state, the claystone is fully saturated. Therefore, swelling can only be induced when the material is brought in contact with water after desaturation, or when it is submitted to an effective stress release. Several authors working on this rock reported an increase of stiffness and mechanical resistance with decreasing water content. Even though specimens are well protected from drying during all handling phases from core extraction to laboratory testing, they desaturate slightly, with a saturation degree between 90 and $95 \%$ generally observed. To evaluate parameters on specimens under well defined saturated conditions, the specimens have to be hydrated in the testing apparatus. Special attention was paid here, as the application of stress during this phase is indispensable for avoiding free swelling and limiting specimen damage. Due to the low permeability of the claystone, the saturation time might become very long, which is why we used adapted testing devices, allowing us to reduce the drainage length of the specimens to $10 \mathrm{~mm}$ (Tang et al., 2008, Belmokhtar et al., 2017b, 2018). Improved testing procedures, presented in detail by Braun et al. (2019) were followed, comprised of step loading, which enable a better distinction between drained and undrained specimen state in the experiments. These time efficient procedures permit us to evaluate several poroleastic coefficients in each loading step, and hence to analyse inter-compatible parameters as a function of the isotropic effective stress.

We refer here also to our companion paper (Braun et al., 2020), in which we investigated the thermal properties of the $\mathrm{COx}$ claystone under constant stress conditions. The present work was carried out under isothermal conditions, without any influence of thermal effects. However, in the companion paper we discuss thermal characteristics in undrained conditions, which are strongly coupled with the hydromechanical properties described in the following.

\section{Poro-Elastic Framework}

In this work we analyse the mechanical response of a porous rock due to external stress and pore pressure loading, based on the poroelastic constitutive equations, first described by Biot and Willis (1957). For a transversely isotropic material one finds identical parameters for both directions $x=y=h$ parallel to the bedding plane and different properties in the direction $z$ (perpendicular to the bedding plane). The transversely isotropic poroelastic stress-strain relationship can be written as (Cheng, 1997):

$\mathrm{d} \sigma_{i}=M_{i j} \mathrm{~d} \varepsilon_{j}+b_{i} \mathrm{~d} p_{f}$

where $\sigma_{i}$ and $\varepsilon_{i}$ denote the stress and strain tensors, respectively, $M_{i j}$ the stiffness matrix, $b_{i}$ the Biot coefficients in the $i$ direction and $p_{f}$ the pore fluid pressure. The strain tensor $\sigma_{i}$ is composed of:

$\sigma_{i}=\left[\sigma_{x}, \sigma_{y}, \sigma_{z}, \sigma_{x y}, \sigma_{y z}, \sigma_{z x}\right]^{\top}$

The planes and directions in which the different stress tensor components and the material properties intervene is schematically represented in Fig. 1. The strains in different directions are contained within the strain vector $\varepsilon_{i}$ :

$\varepsilon_{i}=\left[\varepsilon_{x}, \varepsilon_{y}, \varepsilon_{z}, \varepsilon_{x y}, \varepsilon_{y z}, \varepsilon_{z x}\right]^{\top}$

The vector $b_{i}$ represents the Biot effective stress coefficents in both directions of anisotropy:

$b_{i}=\left[b_{h}, b_{h}, b_{z}, 0,0,0\right]^{\top}$

We can also write the stiffness matrix $M_{i j}$ as follows:

$M_{i j}=\left(\begin{array}{cccccc}M_{11} & M_{12} & M_{13} & 0 & 0 & 0 \\ M_{12} & M_{11} & M_{13} & 0 & 0 & 0 \\ M_{13} & M_{13} & M_{33} & 0 & 0 & 0 \\ 0 & 0 & 0 & 2 G^{\prime} & 0 & 0 \\ 0 & 0 & 0 & 0 & 2 G & 0 \\ 0 & 0 & 0 & 0 & 0 & 2 G\end{array}\right)$

$M_{11}=\frac{E_{h}\left(E_{z}-E_{h} \nu_{z h}{ }^{2}\right)}{\left(1+\nu_{h h}\right)\left(E_{z}-E_{z} \nu_{h h}-2 E_{h} \nu_{z h^{2}}\right)}$

$M_{12}=\frac{E_{h}\left(E_{z} \nu_{h h}+E_{h} \nu_{z h}{ }^{2}\right)}{\left(1+\nu_{h h}\right)\left(E_{z}-E_{z} \nu_{h h}-2 E_{h} \nu_{z h}{ }^{2}\right)}$

$M_{13}=\frac{E_{h} E_{z} \nu_{z h}}{E_{z}-E_{z} \nu_{h h}-2 E_{h} \nu_{z h}^{2}}$

$M_{33}=\frac{E_{z}{ }^{2}\left(1-\nu_{h h}\right)}{E_{z}-E_{z} \nu_{h h}-2 E_{h} \nu_{z h^{2}}{ }^{2}}$

$G^{\prime}=\frac{M_{11}-M_{12}}{2}$ 


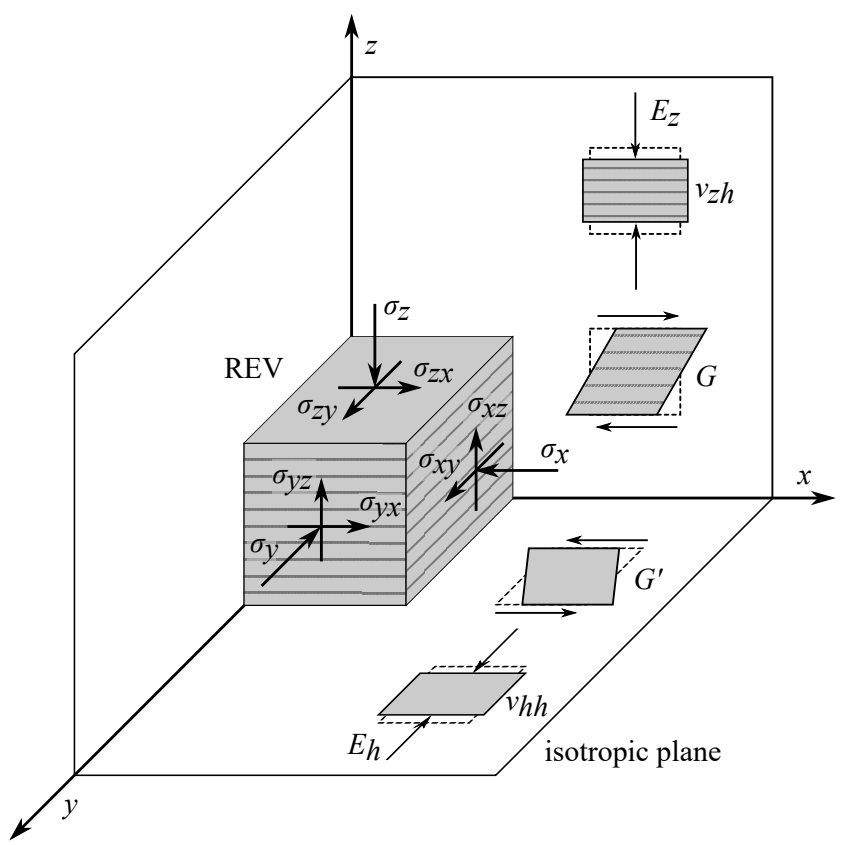

Fig. 1 Representative elementary volume in a transversely isotropic frame, adopted from Popov et al. (2019). The $x-y$ plane corresponds to the isotropic plane. The $z$ axis is oriented perpendicularly to the isotropic plane. Different material properties $E_{i}, \nu_{i}, G$ and $G^{\prime}$ describe the material response within the material planes, where the parameters in the $y-z$ plane (not displayed here) are equal to the ones in the $z-x$ plane.

where $E_{z}$ and $\nu_{z h}$ are the Young modulus and the Poisson ratio perpendicular to the bedding plane, and $E_{h}$ and $\nu_{h h}$ parallel to the bedding plane, respectively. $G$ denotes the shear modulus perpendicular to bedding and $G^{\prime}$ the shear modulus parallel to bedding.

By using the inverse of the stiffness matrix $M_{i j}^{-1}=$ $C_{i j}$, denoted as the drained compliance matrix, one can write:

$\mathrm{d} \varepsilon_{j}=C_{i j} \mathrm{~d} \sigma_{i}-C_{i j} b_{i} \mathrm{~d} p_{f}$

The compliance matrix $C_{i j}$ is written as:

$C_{i j}=\left(\begin{array}{cccccc}C_{11} & C_{12} & C_{13} & 0 & 0 & 0 \\ C_{12} & C_{11} & C_{13} & 0 & 0 & 0 \\ C_{13} & C_{13} & C_{33} & 0 & 0 & 0 \\ 0 & 0 & 0 & 1 /\left(2 G^{\prime}\right) & 0 & 0 \\ 0 & 0 & 0 & 0 & 1 /(2 G) & 0 \\ 0 & 0 & 0 & 0 & 0 & 1 /(2 G)\end{array}\right)$

with

$$
\begin{aligned}
& C_{11}=1 / E_{h} \\
& C_{12}=-\nu_{h h} / E_{h} \\
& C_{13}=-\nu_{z h} / E_{z} \\
& C_{33}=1 / E_{z} \\
& G^{\prime}=E_{h} /\left(1+\nu_{h h}\right)
\end{aligned}
$$

In laboratory experiments, the Young moduli and Poisson ratios are generally measured in a triaxial cell under deviatoric loads. The properties $E_{z}$ and $\nu_{z h}$ are determined on a specimen which is submitted to a deviatoric load perpendicular to the bedding plane $\sigma_{z}$, generating strains $\varepsilon_{z}$ and $\varepsilon_{x}=\varepsilon_{y}$ (Fig. 2). We can then measure $E_{z}=\mathrm{d} \sigma_{z} / \mathrm{d} \varepsilon_{z}$ and $\nu_{z h}=-\mathrm{d} \varepsilon_{x} / \mathrm{d} \varepsilon_{z}$. A specimen, which is loaded in the direction parallel to the bedding plane (e.g. in direction of $y$ ) is required for the remaining properties. Here one is able to observe an axial strain $\varepsilon_{y}$ and two different radial strains $\varepsilon_{x}$ and $\varepsilon_{z}$. This provides $E_{h}=\mathrm{d} \sigma_{y} / \mathrm{d} \varepsilon_{y}, \nu_{h h}=-\mathrm{d} \varepsilon_{x} / \mathrm{d} \varepsilon_{y}$. The measured parameter $\nu_{z h}^{\prime}=-\mathrm{d} \varepsilon_{z} / \mathrm{d} \varepsilon_{y}$ allows us to evaluate of $\nu_{z h}=\nu_{z h}^{\prime} E_{z} / E_{h}$. To be able to determine the shear modulus $G$ perpendicular to the isotropic plane, a third triaxial test is required, where a deviatoric load inclined with respect to the bedding plane is applied. Such loading would result in shear stresses perpendicular to the bedding plane, mobilizing $G$, but also inducing inhomogeneous stress and strain distributions within a specimen, which have to be considered in the analysis. While the shear modulus $G^{\prime}$ is related to the other elastic coefficients (Eq. (10) $), G$ is an independent parameter. The evaluation of $G$ was not carried out in this work and is not further discussed here.

The porosity variation $\mathrm{d} \phi$ is given by:

$\mathrm{d} \phi=-b_{i} \mathrm{~d} \varepsilon_{i}+\frac{1}{N} \mathrm{~d} p_{f}, \quad \frac{1}{N}=\frac{1}{M}-\frac{\phi_{0}}{K_{f}}$

where $M$ is Biot's undrained modulus, $N$ Biot's skeleton modulus and $K_{f}$ the pore fluid bulk modulus. Note that the expression of porosity variation needs an additional poroelastic parameter with respect to the ones presented previously for the stress-strain relation. The Biot modulus $M$ can be expressed according to Aichi and Tokunaga (2012) by:

$$
\begin{gathered}
\quad \frac{1}{M}=2\left(1-b_{h}\right)\left[\frac{\left(1-\nu_{h h}\right) b_{h}}{E_{h}}-\frac{\nu_{z h} b_{z}}{E_{z}}\right]+ \\
+\frac{\left(1-b_{z}\right)}{E_{z}}\left(b_{z}-2 \nu_{z h} b_{h}\right)+\phi_{0}\left(\frac{1}{K_{f}}-\frac{1}{K_{\phi}}\right)
\end{gathered}
$$

with $K_{\phi}$ representing the unjacketed pore modulus (Brown and Korringa, 1975). In undrained conditions, the fluid mass remains constant and we can write $\mathrm{d} m_{f}=\mathrm{d}\left(\rho_{f} \phi_{0}\right)=0$. Together with $\mathrm{d} \rho_{f} / \rho_{f}=\mathrm{d} p_{f} / K_{f}$ and Eq. (14), we obtain an expression for the pore pressure change in undrained conditions:

$\mathrm{d} p_{f}=M b_{i} \mathrm{~d} \varepsilon_{i}$

Using Eq. (1), one can express the pore pressure change $\mathrm{d} p_{f}$ (Eq. (16) ) as a function of total stress change:

$\mathrm{d} p_{f}=\frac{1}{3} B_{i} \mathrm{~d} \sigma_{i}$ 
where:

$B_{i}=\frac{3 b_{j} C_{i j}}{\frac{1}{M}+b_{i} C_{i j} b_{j}}$

$B_{i}$ comprises the anisotropic components of the Skempton coefficient:

$B_{i}=\left[B_{h}, B_{h}, B_{z}, 0,0,0\right]^{\top}$

$B_{z}$ is the Skempton coefficient parallel to bedding and $B_{h}$ the Skempton coefficient perpendicular to bedding, arising from the mathematical framework of transverse isotropy. The classical parameter $B$ used for isotropic materials can here only describe the change of pore pressure under isotropic loading, for which $B=\sum B_{i} / 3$. Under deviatoric loading however, the loading direction influences the amount of generated pore pressure, due to the anisotropic characteristics. Imagine a material with $B_{z}$ higher than $B_{h}$. According to Eq. (17), if this material is loaded in the $z$ direction, it generates a higher pore pressure increase than when loaded by the same amount in the $h$ direction.

Analogously to the drained stiffness matrix, one can determine the undrained stiffness matrix $M_{i j}^{u}$ with (Cheng, 1997):

$M_{i j}^{u}=M_{i j}+M b_{i} b_{j}$

The inverse of the undrained stiffness matrix is the undrained compliance matrix $C_{i j}^{u}$, which provides the undrained Young's moduli $E_{u, i}$ and the undrained Poisson's ratios $\nu_{u, i}$ :

$C_{11}^{u}=1 / E_{u, h}$

$C_{12}^{u}=-\nu_{u, h h} / E_{u, h}$

$C_{13}^{u}=-\nu_{u, z h} / E_{u, z}$

$C_{33}^{u}=1 / E_{u, z}$

For this transversely isotropic relationship under micro-heterogeneity and micro-isotropy assumptions, seven material coefficients (i.e. $E_{h}, E_{z}, \nu_{h h}, \nu_{z h}, b_{h}, b_{z}$, $G)$ describe the stress strain relationship, while three additional parameters $\left(K_{\phi}, \phi_{0}, K_{f}\right)$ are required for the porosity change (Aichi and Tokunaga, 2012).

\subsection{Isotropic stress conditions}

When analysing experiments under isotropic stress conditions, it can be helpful to utilize some poromechanical relationships between volume changes and transversely isotropic deformations. Note that due to the anisotropic framework, the bulk parameters discussed in this section are unable to describe a volume change under mean stress changes in general. Contrary to an isotropic material framework, the parameters can here only be related to isotropic stress changes. Nevertheless, data from isotropic tests can provide complementary information to data from deviatoric stress tests, useful for inferring the complete set of elastic properties.

Under isothermal conditions and isotropic stresses, the volumetric strain $\varepsilon_{v}$ is described with respect to the changes in isotropic Terzaghi effective stress $\sigma^{\prime}=\sigma-p_{f}$ (where $\sigma$ is the total confining stress and $p_{f}$ the pore fluid pressure) as a sum of partial derivatives:

$\mathrm{d} \varepsilon_{v}=\sum \mathrm{d} \varepsilon_{i}=\frac{1}{K_{d}} \mathrm{~d} \sigma^{\prime}+\frac{1}{K_{s}} \mathrm{~d} p_{f}$

in which $K_{d}$ is the isotropic drained bulk modulus and $K_{s}$ the unjacketed bulk modulus (Gassmann, 1951, Brown and Korringa, 1975). We are able to measure the Biot modulus $H$ through a change of pore pressure under constant confining stress, defined as:

$\frac{1}{H}=\frac{1}{V_{0}}\left(\frac{\partial V}{\partial p_{f}}\right)_{\sigma}=\frac{1}{K_{d}}-\frac{1}{K_{s}}$

The isotropic Biot coefficient $b$ is defined as:

$b=1-\frac{K_{d}}{K_{s}}=\frac{K_{d}}{H}$

In undrained conditions, the mass of pore fluid remains constant, which results in a change in volumetric strain and pore pressure through isotropic stress, as follows:

$\mathrm{d} \varepsilon_{v}=\frac{1}{K_{u}} \mathrm{~d} \sigma, \quad \mathrm{d} p_{f}=B \mathrm{~d} \sigma$

Hereby $K_{u}$ is the isotropic undrained bulk modulus and $B$ the isotropic Skempton coefficient $B=$ $\sum B_{i} / 3$ (Skempton, 1954). Following the approach of Belmokhtar et al. (2017b), the moduli $D_{i}, U_{i}$ and $H_{i}$, which describe the anisotropic strain response to isotropic loads, are defined for a drained isotropic compression:

$D_{i}=\left(\frac{\mathrm{d} \sigma}{\mathrm{d} \varepsilon_{i}}\right)_{\mathrm{d} p_{f}=0}$

for an undrained isotropic compression:

$U_{i}=\left(\frac{\mathrm{d} \sigma}{\mathrm{d} \varepsilon_{i}}\right)_{\mathrm{d} m_{f}=0}$

and for a pore pressure loading:

$H_{i}=-\left(\frac{\mathrm{d} p_{f}}{\mathrm{~d} \varepsilon_{i}}\right)_{\mathrm{d} \sigma=0}$ 
We can also define the anisotropy ratios between deformations in $h$ and in $z$ direction with $R_{D}=D_{h} / D_{z}$, $R_{U}=U_{h} / U_{z}$ and $R_{H}=H_{h} / H_{z}$, which provides:

$D_{h}=K_{d}\left(2+R_{D}\right), \quad D_{z}=K_{d}\left(1+\frac{2}{R_{D}}\right)$

$H_{h}=H\left(2+R_{H}\right), \quad H_{z}=H\left(1+\frac{2}{R_{H}}\right)$

The undrained moduli $U_{i}$ are linked to the drained ones with the relationship:

$\frac{1}{U_{i}}=\frac{1}{D_{i}}-B \frac{1}{H_{i}}$

One is able to deduce a relationship between the parameters from isotropic and deviatoric experiments:

$E_{z}=D_{z}\left(1-2 \nu_{z h}\right), \quad E_{h}=\frac{1-\nu_{h h}}{\frac{1}{D_{h}}+\frac{\nu_{z h}}{E_{z}}}$

Also the parallel and perpendicular Biot's coefficients $b_{h}$ and $b_{z}$ can be calculated concurrently (Belmokhtar et al. 2017b):

$b_{h}=\frac{\nu_{z h} / H_{z}+1 / H_{h}}{\nu_{z h} / D_{z}+1 / D_{h}}$

$b_{z}=2 \nu_{z h} b_{h}+\left(1-2 \nu_{z h}\right) \frac{D_{z}}{H_{z}}$

The bulk Skempton's coefficient $B$ can be determined as:

$B=\frac{K_{u}-K_{d}}{b K_{u}}$

and the expression 18 for the two Skempton coefficients $B_{z}$ and $B_{h}$ is simplified to:

$B_{i}=\frac{3 \sum_{j} C_{i j}-\frac{1}{K_{s}}}{\frac{1}{K_{d}}-\frac{1}{K_{s}}} B$

Note that $K_{\phi}$ has to be determined separately in an unjacketed test by measuring the change in pore fluid mass during equal increments of pore pressure and total stress change (e.g. Gassmann, 1951; Brown and Korringa, 1975. Coussy, 2004, Ghabezloo et al., 2008. Makhnenko et al., 2017). This fluid mass change is generally very small for common geomaterials, making the precise measurement a challenging task. For homogeneous materials at the micro-scale, one can assume $K_{\phi}=K_{s}$ (Berryman, 1992). If this is not known a priori, it is practical to use some poromechanical relationships for calculating $K_{\phi}$, as given by Ghabezloo et al. (2008), which provide:

$\frac{1}{K_{\phi}}=\frac{1}{K_{f}}-\frac{\left(1 / K_{u}-1 / K_{d}+1 / H\right)}{\phi_{0} H\left(1 / K_{d}-1 / K_{u}\right)}$

The bulk modulus of the pore space $K_{\phi}$ can hence be calculated by an experimental evaluation of the undrained bulk modulus $K_{u}$, which is less tedious to be determined in an undrained isotropic compression test. The porosity $\phi_{0}$ can be obtained by volume and mass measurements of oven-dried specimens, whereas the bulk modulus of the pore fluid $K_{f}$ is generally known for a specific fluid, such as for example water. If one is able to measure more than the minimum number of eight independent coefficients (i.e. $E_{h}, E_{z}, \nu_{h h}$, $\nu_{z h}, b_{h}, b_{z}, G, K_{\phi}$, given that $\phi_{0}$ and $K_{f}$ are known) experimentally, an overdetermined set of parameters is obtained, which can help to check for a compatibility of these values. In this study we did not investigate $G$, therefore the parameter set which we aimed to characterize contains seven independent coefficients.

\section{Materials and Methods}

\subsection{Specimen preparation}

In this laboratory study we investigated specimens trimmed from COx cores that were extracted at the URL from horizontal boreholes. To preserve the material in its in-situ state as best as possible, that means to avoid desaturation (Ewy, 2015) and mechanical damage, cores were shipped and stored in T1 cells, developed by Andra (Conil et al., 2018). Each cell protects an $80 \mathrm{~mm}$ diameter COx core, which is wrapped in aluminium foil and a latex membrane to prevent drying. A plastic tube is placed around the core and cement is cast between the membrane and the tube, forming a layer of mechanical protection. This minimises, together with a spring system in axial direction, volume changes of the core.

After receiving the cores, the $\mathrm{T} 1$ cells were removed and the cores were immediately covered by a layer of paraffin wax. This protection from drying remained during the following trimming process. Using an aircooled diamond coring bit, cylinders of $38 \mathrm{~mm}$ diameter were trimmed perpendicular and parallel to the bedding plane. The cylinders of $80 \mathrm{~mm}$ height were also covered by a paraffin layer, before being cut into cylinders of 76 $\mathrm{mm}$ height for triaxial tests or disks of $10 \mathrm{~mm}$ height for isotropic tests (Fig. 2), using a diamond wire saw. 
Table 1 Mean and standard deviation (in parentheses) of petrophysical measurements done on cuttings of three COx cores; with wet and dry density $\rho$ and $\rho_{d}$, respectively, porosity $\phi_{0}$, water content $w$, saturation degree $S_{r}$ and suction $s$.

\begin{tabular}{|c|c|c|c|c|c|c|}
\hline Core & $\begin{array}{c}\rho \\
{\left[\mathrm{g} / \mathrm{cm}^{3}\right]}\end{array}$ & $\begin{array}{c}\rho_{d} \\
{\left[\mathrm{~g} / \mathrm{cm}^{3}\right]}\end{array}$ & $\begin{array}{c}\phi_{0} \\
{[\%]}\end{array}$ & $\begin{array}{c}w \\
{[\%]}\end{array}$ & $\begin{array}{c}S_{r} \\
{[\%]}\end{array}$ & $\begin{array}{c}s \\
{[\mathrm{MPa}]}\end{array}$ \\
\hline $\begin{array}{l}\text { EST } \\
53650\end{array}$ & $\begin{array}{c}2.37 \\
(0.00)\end{array}$ & $\begin{array}{c}2.22 \\
(0.01)\end{array}$ & $\begin{array}{l}17.9 \\
(0.2)\end{array}$ & $\begin{array}{c}7.5 \\
(0.1)\end{array}$ & $\begin{array}{l}92.5 \\
(0.8)\end{array}$ & $\begin{array}{l}24.2 \\
(2.1)\end{array}$ \\
\hline $\begin{array}{l}\mathrm{EST} \\
57185\end{array}$ & $\begin{array}{c}2.38 \\
(0.00)\end{array}$ & $\begin{array}{c}2.21 \\
(0.00)\end{array}$ & $\begin{array}{l}18.2 \\
(0.2)\end{array}$ & $\begin{array}{c}7.9 \\
(0.1)\end{array}$ & $\begin{array}{l}95.3 \\
(0.7)\end{array}$ & $\begin{array}{l}17.4 \\
(0.1)\end{array}$ \\
\hline $\begin{array}{l}\text { EST } \\
58132\end{array}$ & $\begin{array}{c}2.39 \\
(0.02)\end{array}$ & $\begin{array}{c}2.22 \\
(0.02)\end{array}$ & $\begin{array}{l}17.9 \\
(0.6)\end{array}$ & $\begin{array}{c}7.8 \\
(0.2)\end{array}$ & $\begin{array}{l}96.3 \\
(3.6)\end{array}$ & $\begin{array}{l}22.8 \\
(1.3)\end{array}$ \\
\hline
\end{tabular}

For protection during storage, the specimens were enveloped by an aluminium foil, covered by a mixture of $70 \%$ paraffin wax and $30 \%$ Vaseline oil.

We carried out a petrophysical characterization, directly after trimming the specimens, and after several months in storage. Table 1 shows the measured characteristics, determined on cuttings of the cores. We obtained the specimen volume through hydrostatic weighting in in low-odour hydrocarbon to determine their volume. The dry density was obtained after oven drying at $105{ }^{\circ} \mathrm{C}$. For the porosity calculation, a solid density $\rho_{s}=2.69 \mathrm{~g} / \mathrm{cm}^{3}$ (Conil et al. 2018) was assumed. A chilled mirror tensiometer (WP4, Decagon brand) provided measurements of the suction $s$. The relatively high degree of saturation measured after opening the $\mathrm{T} 1$ cells indicates a good drying protection within the cells. In addition, suction and saturation degree were measured on cuttings which were protected and stored in the same way as the specimens. No significant change of these properties was observed during storage, which confirms the effectiveness of the adopted protection methods and a good preservation of the natural water content.

\subsection{Isotropic compression cell}

For the laboratory investigations, we used a highpressure isotropic thermal compression cell, which is presented in Fig. 3 (Tang et al. 2008, Mohajerani et al., 2012, Belmokhtar et al., 2017a b: Braun et al., 2019). This cell allows us to test specimens with $38 \mathrm{~mm}$ diameter and variable height, placed inside a neoprene membrane in the center of the cell. A silicone heating belt is wrapped around the isotropic cell, which is able to heat up the device. The belt is coupled with a temperature sensor in the vicinity of the specimen, which allows us to maintain a constant cell temperature or impose heating/cooling under constant rates. The cell is filled with silicone oil, which can be set under a pressure of up to $40 \mathrm{MPa}$ by a pressure volume controller (PVC 1, GDS brand). The neoprene membrane isolates the specimen from the silicone oil, so that the pressure of the pore fluid can be controlled independently. The pore pressure is applied from the bottom of the specimen through a porous disk connected to the pressure volume controller PVC 2. During the experiments, we measure the specimen strains locally, using an axial and a radial strain gage (Kyowa brand), glued on the surface of the specimen (Fig. 22.

\subsection{Triaxial compression cell}

A conventional rock mechanics high pressure triaxial cell was used for experiments with deviatoric loading (Fig. 4). A triaxial cell is indispensable for determining the Young moduli and Poisson ratios, necessary for a complete transverse isotropic parameter set. The device used is similar to the isotropic cell, including a pressurized chamber connected to PVC 2, which applies confining pressure to the cylindrical specimen $(38 \mathrm{~mm}$ diameter, variable height). The specimen, isolated by a neoprene membrane, is submitted to pore pressures through porous stones on its top and bottom surfaces, controlled by PVC 3. Specimen deformations are detected by strain gages attached at specimen mid-height (Fig. 2). The same heating system as in the isotropic cell was used for this device, with a silicone heating belt, connected to an internal thermocouple to regulate the cell temperature. The main difference to the isotropic cell is the auto-compensated piston, which allows us to apply axial deviatoric loads. An auto-compensation chamber pressurized by the confining fluid $\sigma_{\text {rad }}$ (situated in the piston housing, not shown in Fig. (4) keeps the piston in equilibrium, when the pressure applied by PVC 1 is zero. In this case, the specimen is in an isotropic stress state where both axial and radial total stresses are equal $\left(\sigma_{\mathrm{ax}}=\sigma_{\mathrm{rad}}\right)$. The pressure applied by PVC 1 controls then only the additional deviatoric part of the stress $q=\sigma_{\mathrm{ax}}-\sigma_{\mathrm{rad}}$ (e.g. Fortin et al. 2005).

\subsection{Testing Procedure}

The COx specimens were mounted in the isotropic and triaxial cells in their initial state at $25{ }^{\circ} \mathrm{C}$. An initial sequence of consolidation, saturation and in-situ stress application was followed, shown schematically in Fig. 5.

First, the specimens were consolidated at constant water content under isotropic stress with a loading rate of $0.1 \mathrm{MPa} / \mathrm{min}$, while the drainage system was kept 


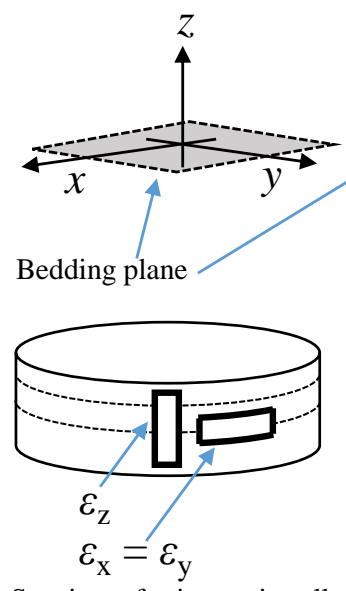

Specimen for isotropic cell
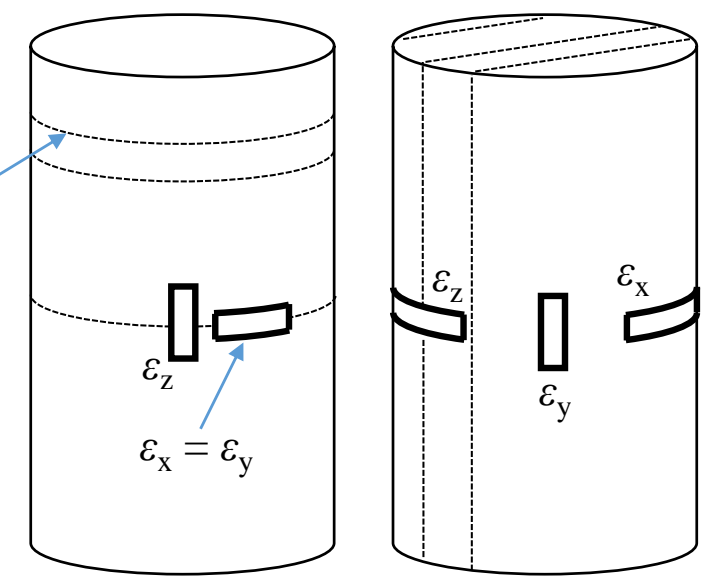

Specimen for triaxial cell

Fig. 2 Strain gages, oriented and attached with respect to the bedding plane of the COx specimens.

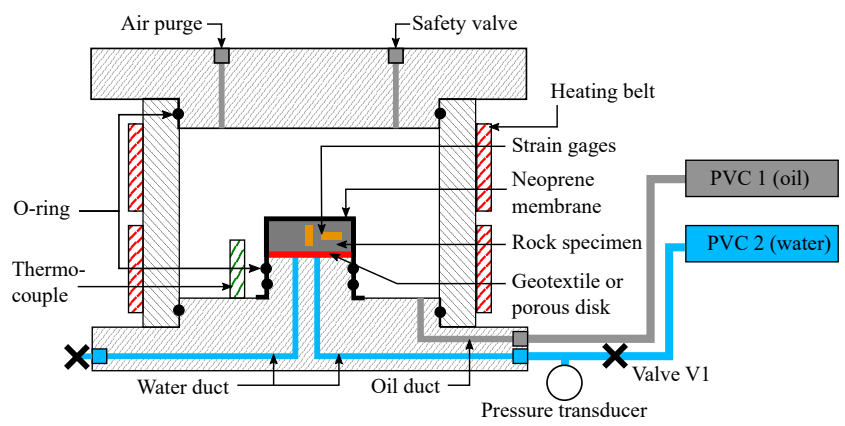

Fig. 3 Temperature controlled high pressure isotropic cell, accommodating a rock specimen equipped with strain gages.

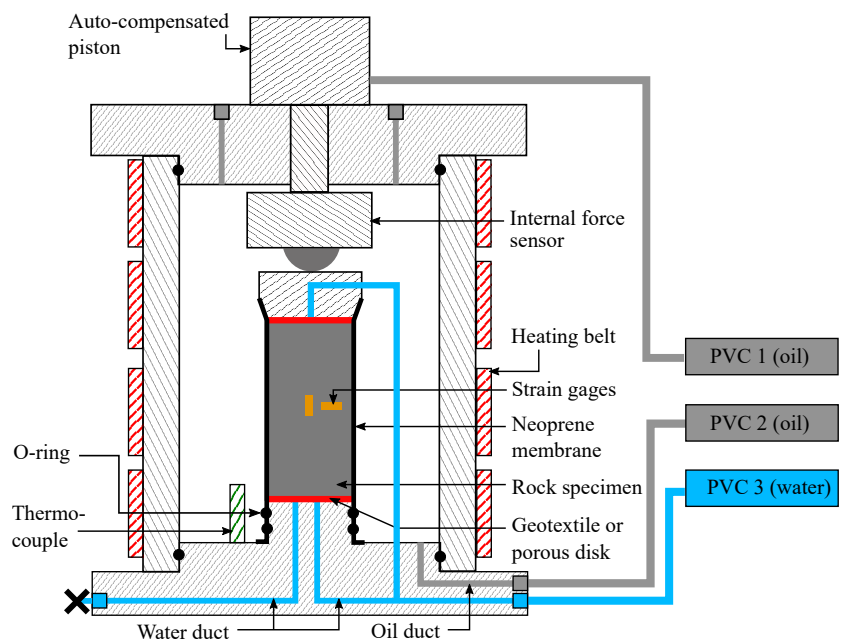

Fig. 4 Temperature controlled high pressure triaxial cell with an auto-compensated load piston and strain gage measuring system.

dry. Most of the specimens were brought to a confining pressure close to the in-situ effective stress between 8 $\mathrm{MPa}$ and $10 \mathrm{MPa}$. Three specimens were brought to a higher confining stress to investigate the effect of confin-

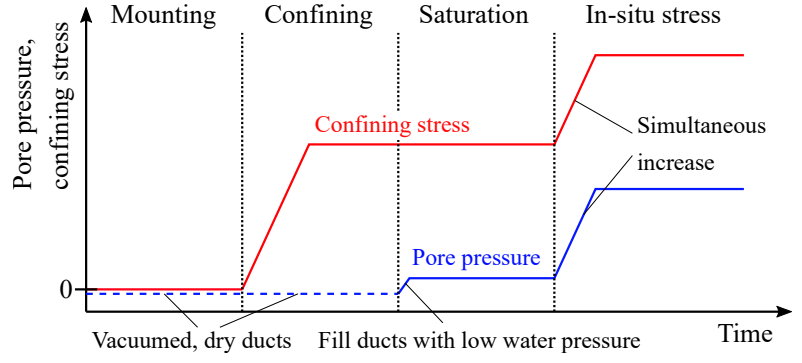

Fig. 5 Mounting and saturation procedure for COx specimens. Specimens are first mounted with dry water-ducts. Vacuum is applied to the ducts in order to evacuate air. The isotropic confining stress is then increased and kept constant. When monitored strains are stable, the water saturation is started with a low back pressure to limit poroelastic strains. After the hydration swelling stabilized, both pore pressure and confining stress are increased simultaneously until the desired stress level close to the in-situ one is reached. Again, strains are monitored and when the deformations are in equilibrium, further testing can be started.

ing pressure on swelling strains during the following hydration. An overview of all tested specimens with their respective initial confining stress is given in Table 2

When specimen deformations remained stable after application of the confining stress, we assume hydraulic equilibrium and a complete dissipation of any generated over-pressure in the pores during the loading, similar to the end of secondary consolidation in soils. The air in the dry drainage ducts was evacuated by vacuum for several minutes and the ducts were then filled with synthetic pore water under a pressure of $100 \mathrm{kPa}$. To prepare synthetic water, salts were added to de-mineralized water according to a recipe provided by Andra, to obtain a fluid composition close to the in-situ one. When injecting pore fluid into a initially partially unsaturated 
Table 2 Overview of tested specimens with their initial saturation phase under stress and their respective subsequent loading paths; the inclined arrows $(\searrow, \nearrow$ ) indicate that several load steps were carried out between mentioned effective stresses.

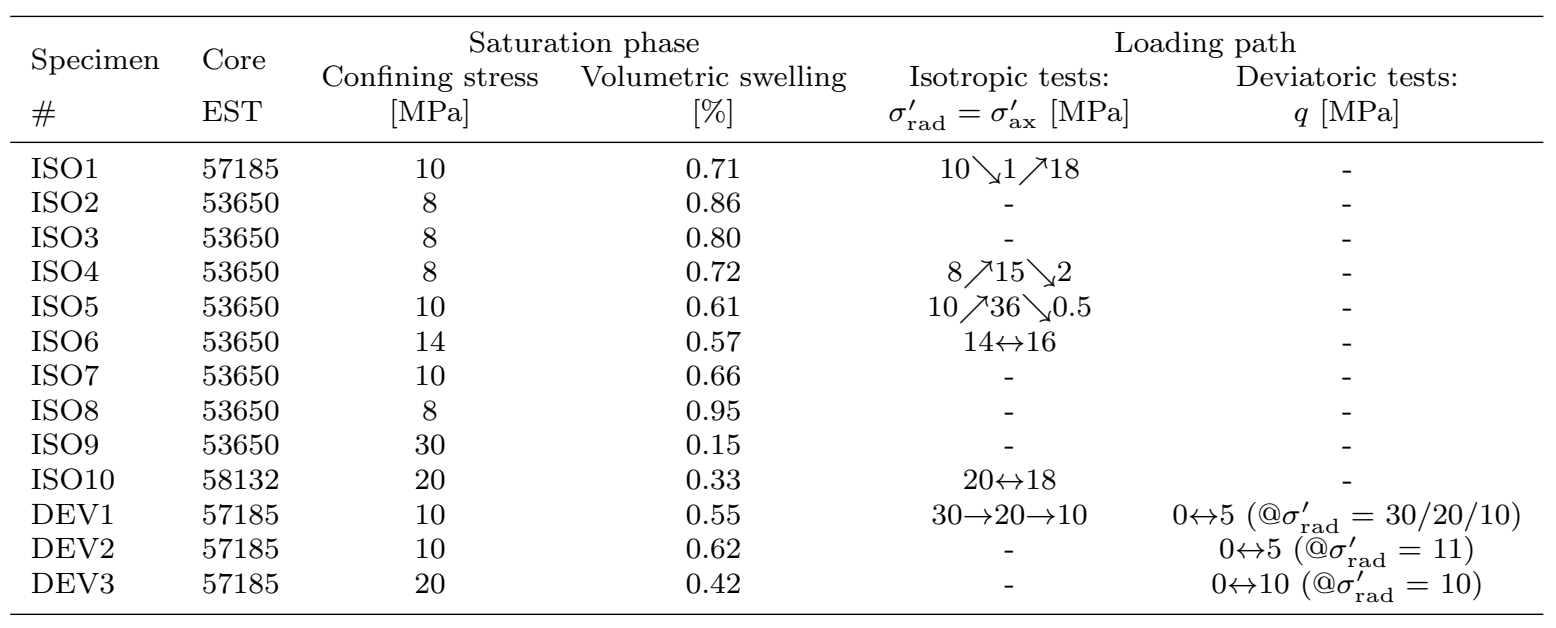

specimen, we expect a total volume increase composed of i) the volume changes of an unsaturated medium due to the reduction of suction and the adsorption of water and ii) the poroelastic response of a saturated medium due to pore pressure increase. The former occurs, when the pore pressure increases from a negative value (corresponding to suction) to zero, while the latter happens under positive pore pressure changes, once the medium is saturated. In order to better distinguish these effects in the experiments, and generate first a predominantly unsaturated response, the initially applied water pressure was chosen relatively small. In this way, we try to limit poroelastic deformations due to pore pressure changes and observe hydration strains only. A certain positive pressure is however required to fill and saturate the drainage lines of the device. Hydration resulted in swelling strains that stabilized after about five days on all specimens, showing similar transient characteristics. Tab. 2 lists the measured volumetric swelling strains, which decrease with increasing confining stress (Fig. 6). Here we neglect however possible size effects due to different specimen dimensions and a potentially incomplete saturation at $100 \mathrm{kPa}$ pore pressure.

After hydration, pore pressure and confining pressure were increased simultaneously by $4 \mathrm{MPa}$ under a constant Terzaghi effective stress. The applied pressures were increased until the pore pressure reached $4 \mathrm{MPa}$. Consequently, the specimens reached Terzaghi effective stresses, which were equal to the initial confining stress in the saturation phase described in Table 2. We can assume complete saturation when the recorded strains stabilized, indicating hydraulic equilibrium. Rad and Clough (1984) conducted calculations based on Boyle's and Henry's laws to estimate the necessary back-pressure for a complete dissolution of the

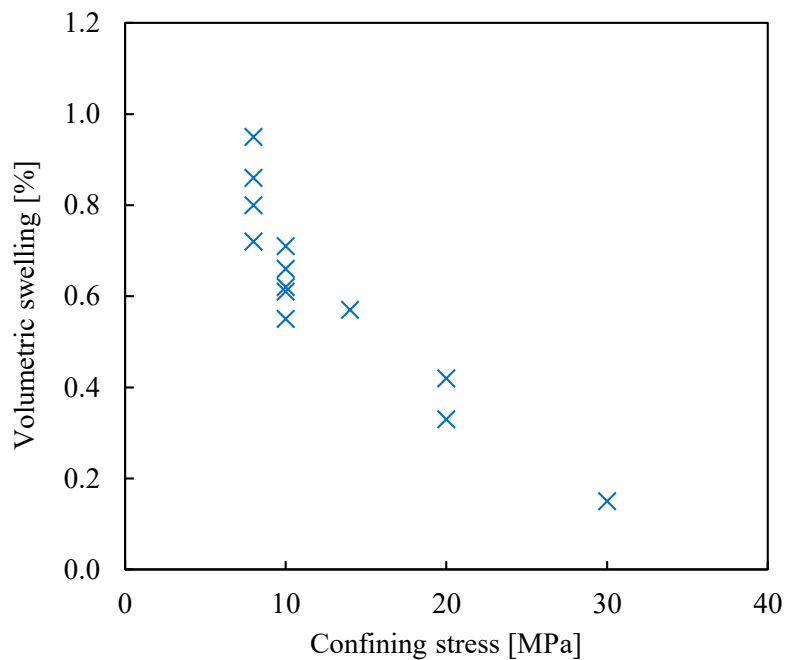

Fig. 6 Measured swelling strains of specimens during hydration under $100 \mathrm{kPa}$ pore pressure and various confining stresses.

air trapped in pores. They showed that for saturating a specimen which is initially saturated at $90 \%$ and submitted to a vacuum of $80 \mathrm{kPa}$, one requires around 150 $\mathrm{kPa}$ back pressure. Here, while having the same saturation degree and imposed vacuum, we applied a much higher pore pressure of $4 \mathrm{MPa}$. Favero et al. (2018) carried out tests of the Skempton coefficient of initially unsaturated Opalinus clay at different pore pressure levels. For pore pressures higher than $2 \mathrm{MPa}$, they found that the Skempton coefficient remained stable, which indicated complete saturation. Note that during this last saturation phase, no distinction of the measured strains between poroelastic deformations and possible additional swelling (due to further saturation by the increasing back-pressure) could be made. 
A step testing procedure, presented by Braun et al. (2019), was then utilized to determine the poroelastic parameters of the material in isotropic tests. This procedure (Fig. 7) consists of increasing or decreasing the confining pressure rapidly at a rate of $0.1 \mathrm{MPa} / \mathrm{min}$ and keeping it then constant at a certain level $(\Delta \sigma)$. This generates first an undrained response, which permits evaluation of the undrained bulk modulus $K_{u}$ (Eq. 25) ) as a tangent modulus, together with the anisotropic moduli $U_{h}$ and $U_{z}$ (Eq. 27)). During a constant load phase, the pore pressures generated in the first phase are allowed to drain by releasing the undrained pore pressure changes through the drainage valve. A drained response can be observed, when all pore pressures have dissipated and the deformations stabilize, providing the drained bulk modulus $K_{d}$ (Eq. 221) with $D_{h}$ and $D_{z}$ (Eq. (26)). When the confining pressure is held constant and the imposed pore pressure is changed instantly $\left(\Delta p_{f}\right)$ by the PVC, a transient deformation can be observed. After stabilization of these deformations, the Biot modulus $H$ (Eq. (23)) with $H_{h}$ and $H_{z}$ (Eq. (28) ) can be evaluated. This pore pressure loading step can also be carried out independently of a precedent confining pressure loading.

In the deviatoric tests we proceeded similarly to the isotropic loading tests, by applying the deviatoric load $q$ in a relatively rapid loading of $0.1 \mathrm{MPa} / \mathrm{min}$, where we assume undrained conditions. In this phase, we determine the undrained coefficients $E_{u, i}$ and $\nu_{u, i}$ (see also Sec. 2 for the parameter definitions and their evaluation) from the initial slopes of the measurements of stress and strain changes (Fig. 8). Once the target deviatoric stress is reached, we keep it constant, causing a fluid dissipation and equilibration of the pore pressure field inside the specimen. We assume completed drainage when measured strains stabilize. Doing so, we can assure drained conditions before and after each step loading. One can evaluate the drained Young's moduli and Poisson's ratios as secant parameters, comparing strains and stresses in the drained states before and after the step. Deviatoric tests on specimens DEV1 and DEV3 were conducted perpendicular to the bedding plane, providing $E_{z}, \nu_{z h}, E_{u, z}$ and $\nu_{u, z h}$ (compare Fig. 2), whereas the test parallel to the bedding plane on DEV2 provided $E_{h}, \nu_{h h}, \nu_{z h}^{\prime}, E_{u, h}, \nu_{u, h h}$ and $\nu_{u, z h}^{\prime}$.

Undrained conditions during the step increase of $q$ were verified in a single, quick unloading/reloading cycle on specimen DEV2 (Fig. 9). We observe a constant stress-strain slope with no hysteresis after the change of loading direction (Fig. 8a). In parallel, constant slopes indicating constant $\nu_{u, i}$ are observed in Fig. 8b. In a perfectly poroelastic material, a hysteresis can only ap- pear due to time dependent fluid diffusion processes. If the loading is fast enough, no diffusion occurs, as the specimen remains in constant undrained conditions. In the same test, after the rapid loading (Fig. 8, 9), one can see the additional fluid-dissipation-induced strains with respect to time, as a transient between undrained and drained state.

For isotropic tests $\left(\sigma^{\prime}=\sigma_{\mathrm{ax}}^{\prime}=\sigma_{\text {rad }}^{\prime}\right)$, the measured parameters are hereafter presented with respect to the mean between initial and final effective stress applied during each step test, i.e. a parameter measured under a step increase from 4.0 to $6.0 \mathrm{MPa}$ is shown as a datapoint at 5.0 MPa. All discussed coefficients were measured under unloading or reloading and are therefore supposed to be elastic. Several subsequent step tests were carried out, starting from the initial stress level and then gradually increasing or decreasing the effective stress in each step with an increment of between 1.0 and $5.0 \mathrm{MPa}$ stress (Fig. 10). These ramps are indicated in Tab. 2 with inclined arrow symbols $(\searrow, \nearrow)$. Horizontal arrows $(\rightarrow)$ characterise only one step between the indicated effective stresses, which was repeated in the case of a double arrow $(\leftrightarrow)$. The same applies for the deviatoric tests on specimens DEV1 - DEV3. Specimen DEV1 was loaded and unloaded by applying a devatoric load $q$ between 0 and $5 \mathrm{MPa}$, which was repeated at effective radial stresses $\sigma_{\text {rad }}^{\prime}$ of 30, 20 and $10 \mathrm{MPa}$. Specimens DEV2 and DEV3 were only tested at $11 \mathrm{MPa}$ and $10 \mathrm{MPa}$ effective radial stress, respectively. The resulting parameters are plotted with respect to the average of the inital and final isotropic effective stress $\sigma^{\prime}$ at each step loading. Specimens without any loading path given in Table 2 were not tested under hydro-mechanical experiments. They were either only tested in thermal tests (not discussed here) or had to be abandoned due to technical problems, and are listed only for their data on the swelling upon resaturation.

\section{Experimental results}

\subsection{Stress dependent behaviour under isotropic loading}

The conducted isotropic hydromechanical tests provided measurements of the moduli $K_{d}$ and $H$ with a strong dependency on the effective stress, consistent for all tested specimens (Fig. 11 and 12). Zimmerman et al. (1986) showed, that under the condition of a constant modulus $K_{s}$, a stress dependency of the tangent bulk moduli of an isotropic material can be expressed as a function of the Terzaghi mean effective stress. In Section 5 we demonstrate, that assuming a constant $K_{s}$ we are indeed able to reproduce the measured COx properties. As the COx claystone is not isotropic, we decided 


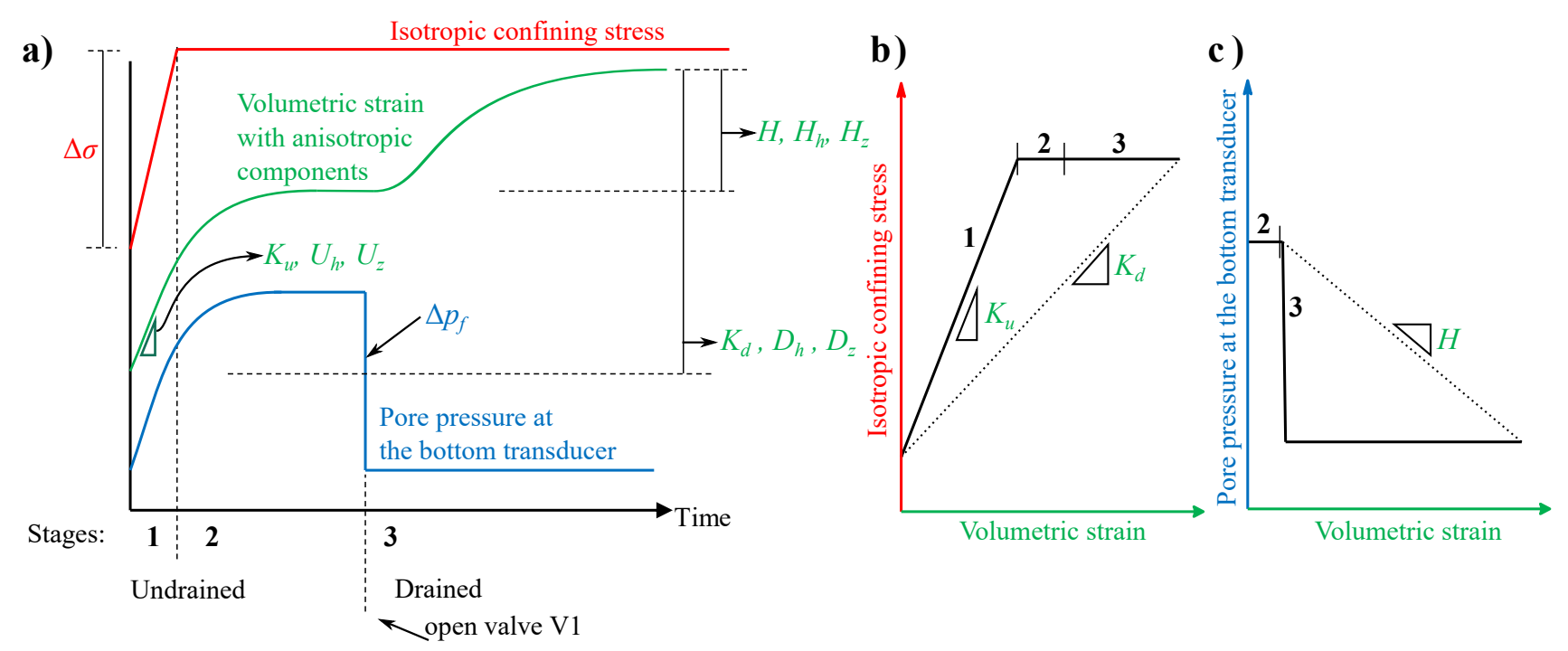

Fig. 7 Schematic representation of the step testing procedure, adopted from Braun et al. (2019) and Hart and Wang (2001). a) Applied and measured changes of stress, pore pressure and strain with time. A rapid increase of the confining stress $\Delta \sigma$ allows us to measure the undrained properties $K_{u}$ (Eq. (25)), $U_{h}$ and $U_{z}$ (Eq. 27p) from the initial slope of the stress-strain response, shown in b). The drainage system is closed in this phase. After pore pressure and strain remain constant, the drainage system is opened and a change of pore pressure $\Delta p_{f}$ is imposed. This pore pressure change creates a strain response, providing us the (secant) Biot modulus $H$ in c) (see also Eq. 23p), with $H_{h}$ and $H_{z}$ (Eq. 28p). The drained parameters $K_{d}$ (Eq. 22p), $D_{h}$ and $D_{z}$ (Eq. 26p) are measured from the secant of the strain response in drained state, before and after the test, as shown in b).

a)

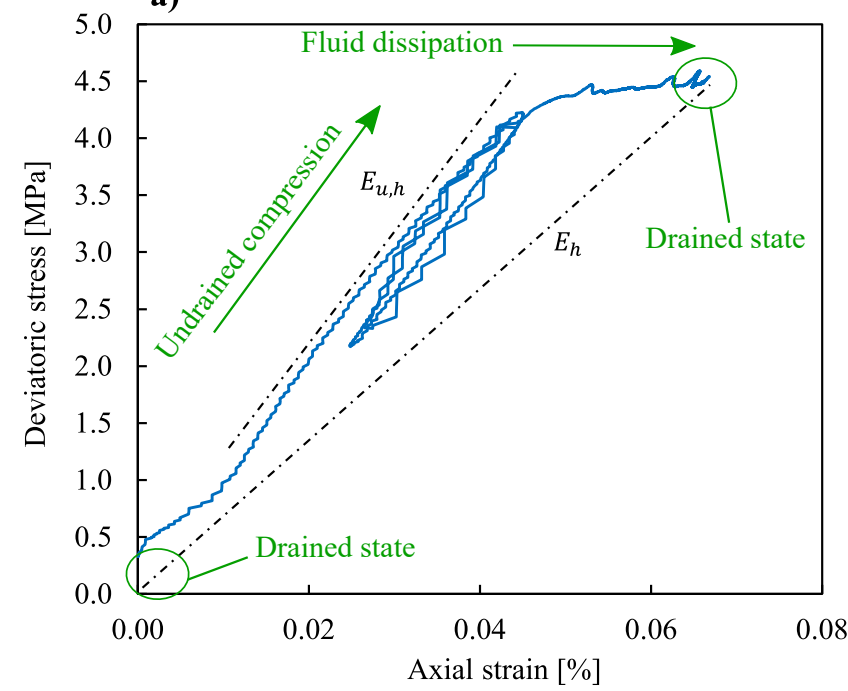

b)

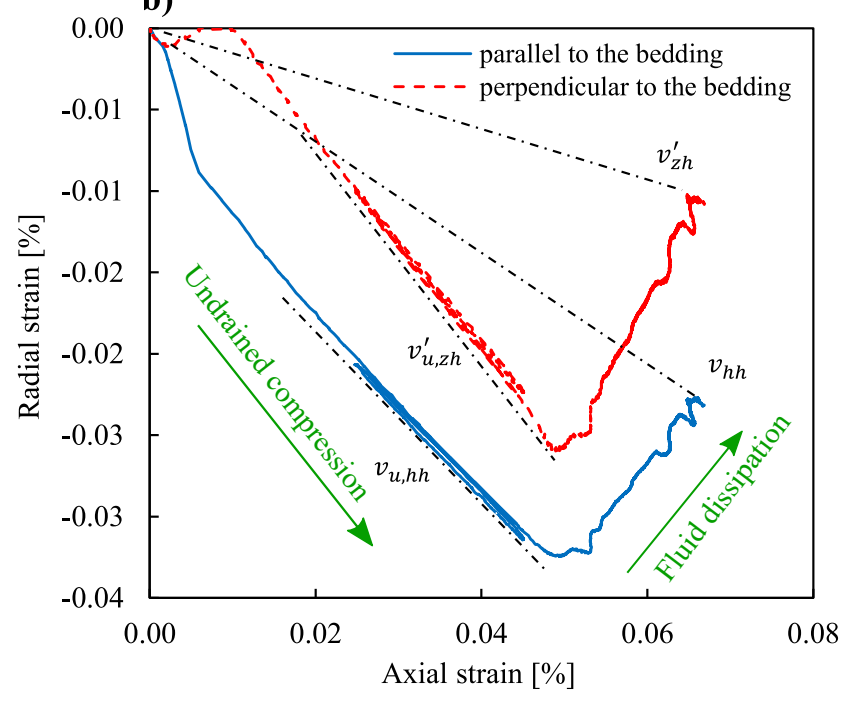

Fig. 8 Measured deformations during a deviatoric test on specimen DEV2 loaded parallel to the bedding plane in a) function of deviatoric stress $q$, highlighting the determination of the Young moduli. The fast loading shows a linear undrained response, while pore pressure diffusion induces further compression with time, once the deviatoric stress is held constant. Note that a fast unloading reloading cycle was only carried out for this specific specimen. No drainage effects in form of a hysteresis were found during the cycle, evidencing a constant undrained condition. b) Radial strains with respect to axial strains indicating the Poisson ratios, also describing a clear difference between undrained response under fast loading and time dependent fluid dissipation, until reaching drained condition. 
a)

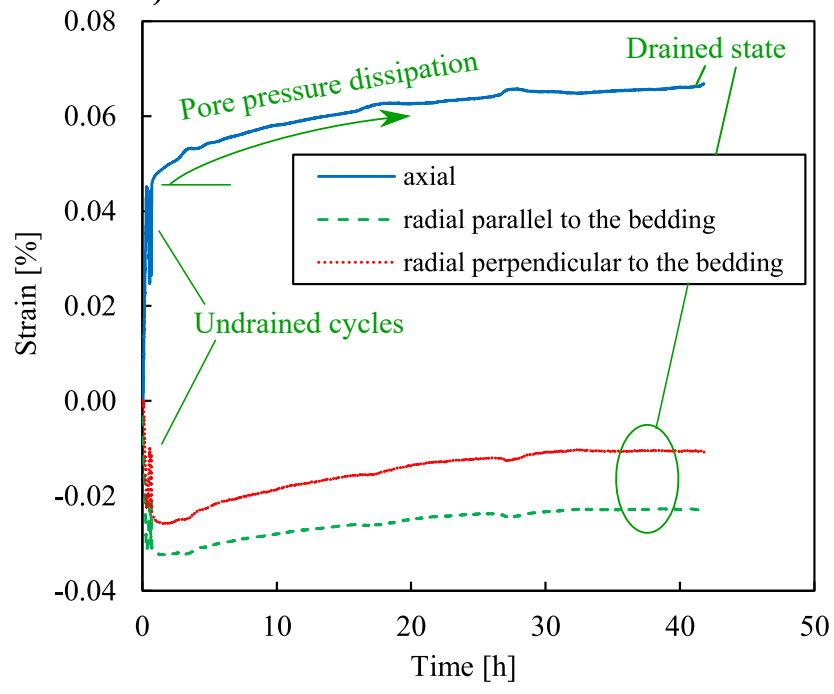

b)

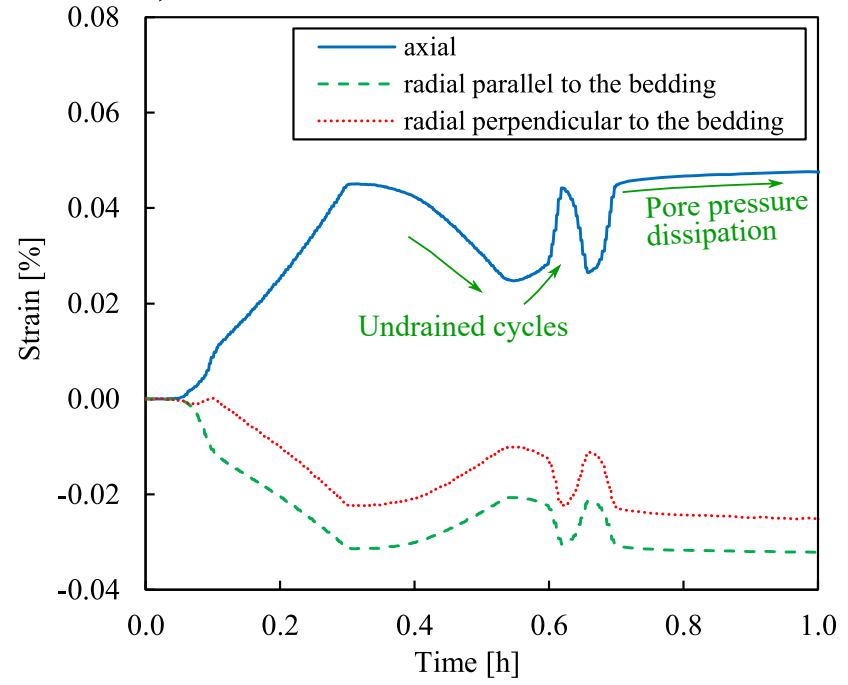

Fig. 9 Measured deformations during a deviatoric test on specimen DEV2 loaded parallel to the bedding plane in a) function of time, with b) zoom on the first hour of a).

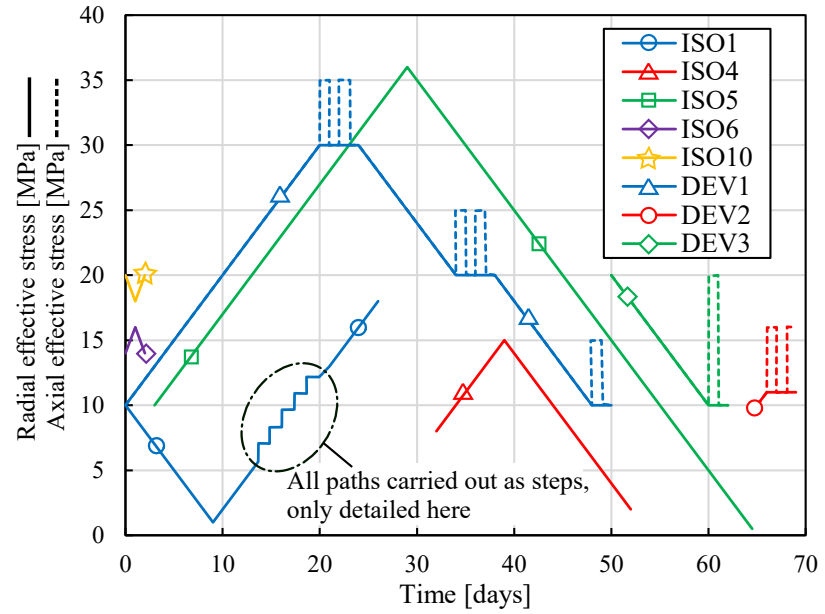

Fig. 10 Schematic representation of the loading paths carried out in this work. The ISO specimens were loaded in steps by changing isotropic confining stress or pore pressure. Note that the inclined lines represent several step loadings, which were not detailed here. Also the DEV specimens were submitted isotropic step loading (solid line), and to additional deviatoric loadings (dashed line) in the form of step-cycles of axial stress. The constant load phase after each isotropic or deviatoric step lasted for at least one day, in order to attain a pore pressure equilibrium. For a better overview, the loading paths were assembled with offsets in the time axis.

here to present the following measurements with respect to the Terzaghi isotropic effective stress. The evaluated parameters are later analysed in Sec. 5 as representative functions of the isotropic effective stress.

The moduli $K_{d}$ and $H$ are smaller than 1.0 GPa for low Terzaghi effective stresses and increase with increasing effective stress (Fig. 11 and 12. With an ef- fective stress larger than around $20 \mathrm{MPa}$, the moduli appear to remain constant, with values of around 3.0 and 3.5 GPa, respectively. For $K_{d}$ at effective stresses around $10 \mathrm{MPa}$, we can observe a good agreement with the findings of Mohajerani (2011) and Belmokhtar et al. (2017b). The modulus $H$ was previously measured by Belmokhtar et al. (2017b) at around $10 \mathrm{MPa}$ effective stress with 3.47 and $2.24 \mathrm{GPa}$, somewhat higher than the present findings.

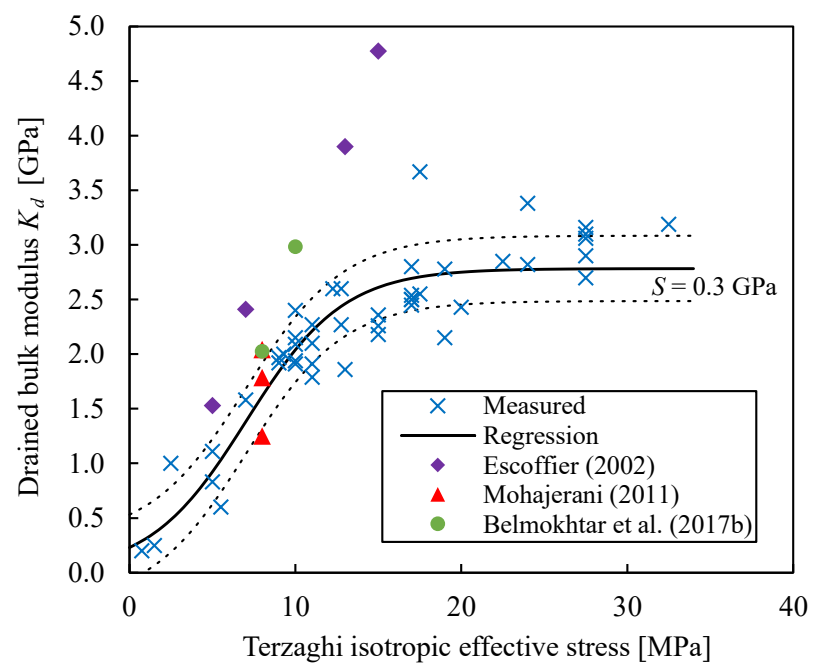

Fig. 11 Measured stress dependent drained bulk modulus $K_{d}$ compared with a fitted parameter set (Sec. 5. $S$ and dotted lines indicate the standard deviation of the regression.

Interestingly, the reduction of stiffness with effective isotropic stress appears to be reversible, as can be seen in Fig. 13. Here we compare the drained bulk modulus, 


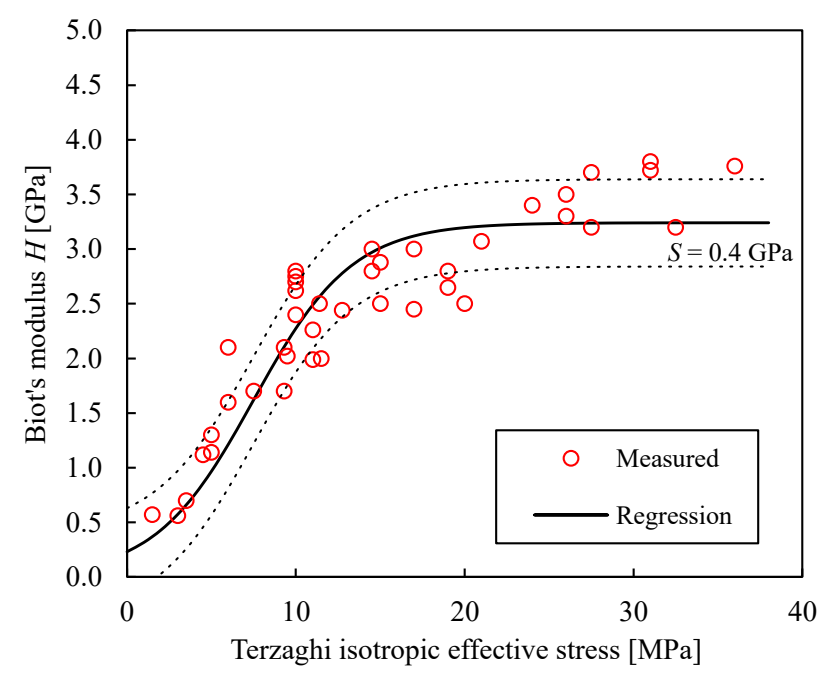

Fig. 12 Measured stress dependent Biot's modulus $H$ compared with a fitted parameter set (Sec. 5). $S$ and dotted lines indicate the standard deviation of the regression.

measured on specimen ISO1 after subsequent unloading steps, starting from the initial under-stress-saturated state. The bulk modulus decreases through unloading. After reloading, the drained bulk modulus comes back to the same level as before unloading, comparable also to the values on ISO6 and ISO10, for which the effective stress level was not significantly reduced after saturation.

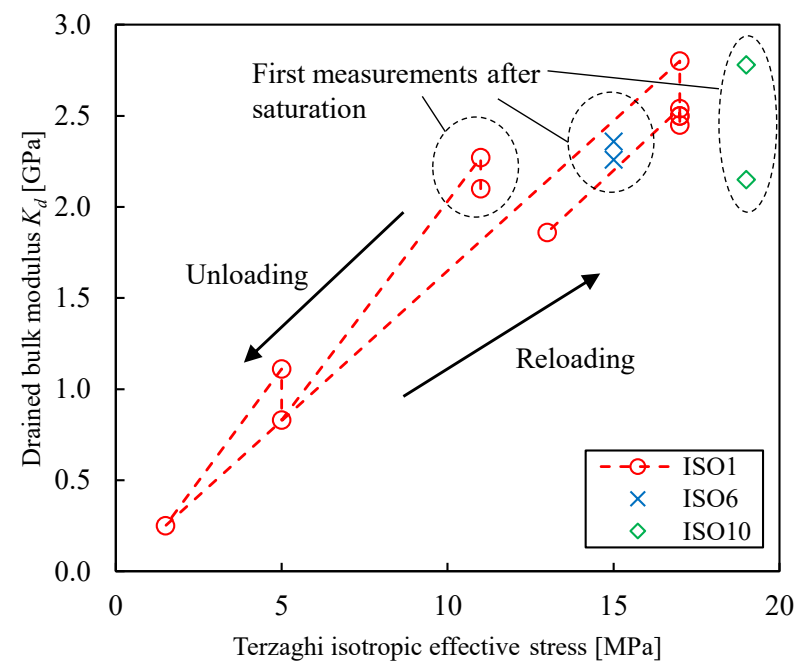

Fig. 13 Measured stress dependent drained bulk modulus $K_{d}$ on specimens ISO1, ISO6 and ISO10, illustrating the reversible reduction of stiffness with decreasing effective stress.

For the undrained bulk modulus $K_{u}$ it is difficult to identify a stress dependency (Fig. 14), due to the rather large dispersion of observed values, which was also evidenced in previous studies
(Escoffier, 2002; Mohajerani, 2011; Belmokhtar et al., 2017b).

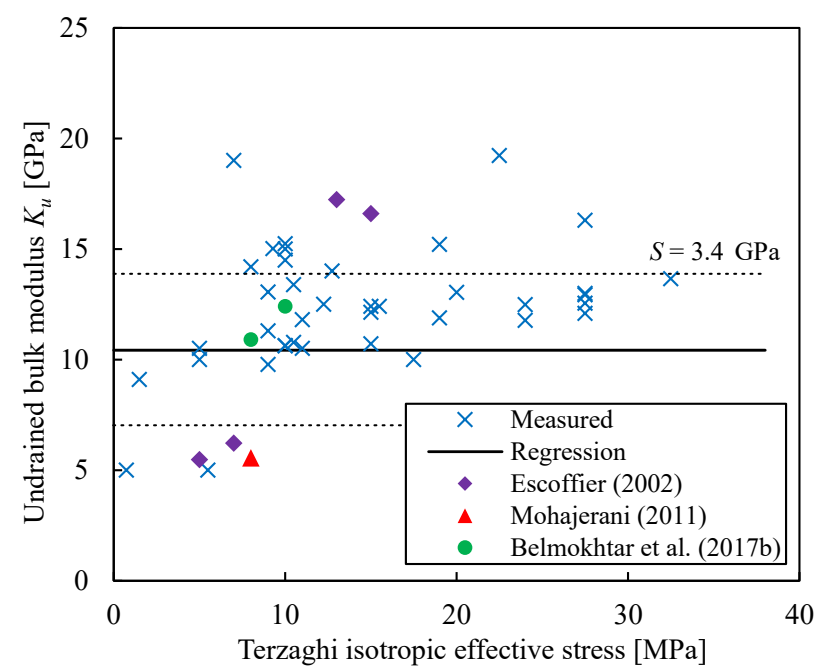

Fig. 14 Measured undrained bulk modulus $K_{u}$, compared with a fitted parameter set (Sec. 5). $S$ and dotted lines indicate the standard deviation of the regression.

The transversely isotropic strain response was recorded simultaneously with $K_{d}, H$ and $K_{u}$ in all tests, resulting in the parameters $D_{i}, H_{i}$ and $U_{i}$. (Fig. 15, 16 and 17). For drained tests $\left(D_{i}, H_{i}\right)$ above $20 \mathrm{MPa}$ effective stress, one observes axial strains perpendicular to the bedding plane about three times larger than radial ones. In undrained tests, the ratio of anisotropy varied more significantly with effective stress, with values around 1.5 for low effective stress and values around 2.0 for $30 \mathrm{MPa}$ effective stress. Again, the rather large scatter with some outliers of the measured undrained properties becomes visible on the parameters $U_{i}$ (Fig. 17.

4.2 Stress dependent behaviour under deviatoric loading

In the triaxial tests, we measured $E_{z}$ and $\nu_{z h}$ on specimens DEV1 and DEV3 for effective confining stresses from 10 to $30 \mathrm{MPa}$ (Fig. 18, 19). Whereas the Poisson ratio remained more or less constant with values between 0.10 and 0.17 , the Young modulus $E_{z}$ increased with increasing confining stress from around 3.4 to $6.7 \mathrm{GPa}$. Compared with the values of $E_{z}$ from Zhang et al. (2012), Menaceur et al. (2015) and Belmokhtar et al. (2018), a similar stress dependency can be observed. The parameters $E_{h}$ and $\nu_{h h}$ on specimen DEV2 were measured only for $10 \mathrm{MPa}$ isotropic effective stress, with values for $E_{h}$ between 6.4 and 8.0 


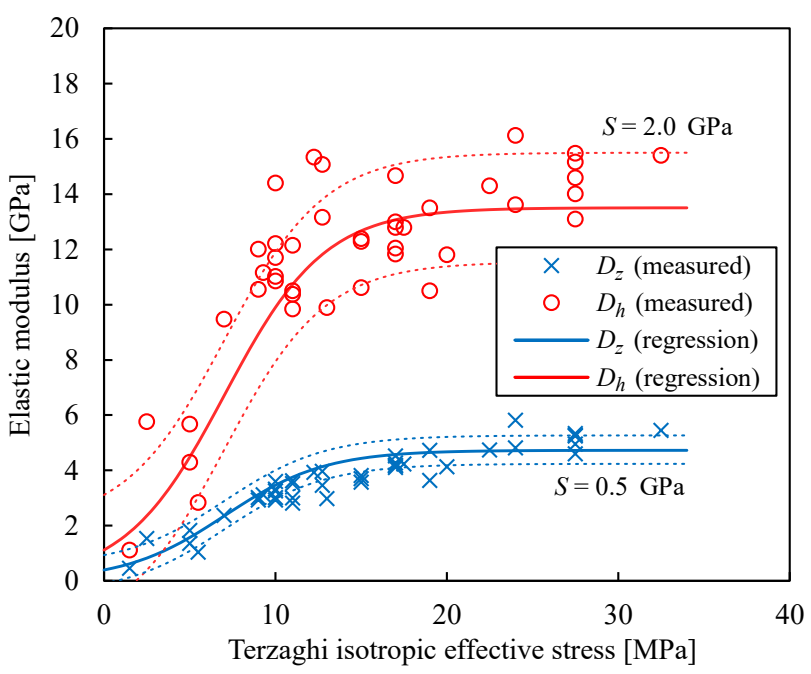

Fig. 15 Measured anisotropic responses $D_{i}$ during drained compression, compared with a fitted parameter set (Sec. 5 ). $S$ and dotted lines indicate the standard deviation of the regression.

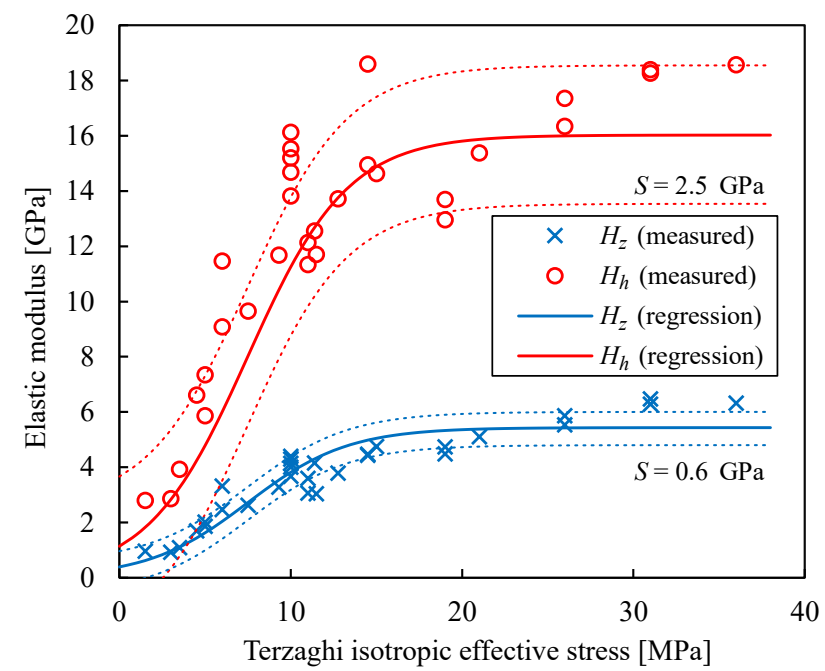

Fig. 16 Measured anisotropic responses $H_{i}$ during pore pressure tests, compared with a fitted parameter set (Sec. 5). $S$ and dotted lines indicate the standard deviation of the regression.

GPa and $\nu_{h h}$ between 0.30 and 0.34 . Note that only two measurements with a relatively large difference were taken for this loading direction.

As expected, the undrained response during triaxial tests produced higher moduli than the drained ones. The parameter $E_{u, z}$ was found between 6.4 and 8.6 GPa and $E_{u, h}$ between 9.8 and $10.8 \mathrm{GPa}$ (Fig. 20). The anisotropy of the undrained moduli shows a ratio $E_{u, h} / E_{u, z}$ around 1.4, whereas the drained moduli show a ratio $E_{h} / E_{z}$ of around 1.8 . Interestingly, we can observe relatively large undrained Poisson's ratios, with values higher than 0.35 and a significant scatter (Fig. 21 . In contrast to isotropic elastic materials, the Pois-

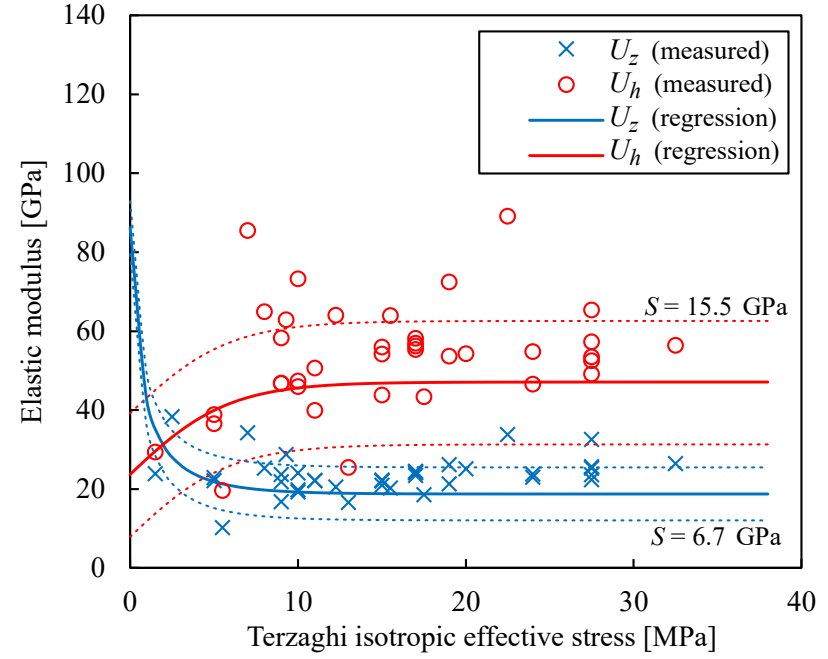

Fig. 17 Measured anisotropic responses $U_{i}$ during undrained compression, compared with our best-fit parameter set (Sec. 5). $S$ and dotted lines indicate the standard deviation of the regression.

son ratios of anisotropic elastic materials have in theory no bounds (Ting and Chen, 2005). High Poisson ratios $\nu>0.5$ have been observed on rocks in the laboratory (e.g. Vutukuri et al., 1974, Hatheway and Kiersch, 1982, Islam and Skalle, 2013), which can be related to significant anisotropy (Gercek, 2007). As for $E_{h}$ and $\nu_{h h}$, note that only two measurements have been made for $E_{u, h}$ and $\nu_{u, h}$, which show a relatively large difference.

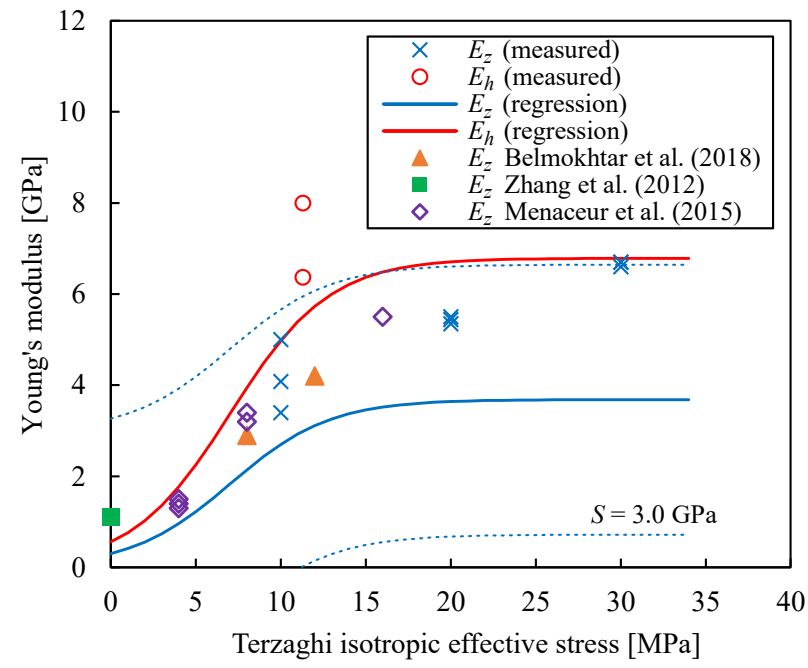

Fig. 18 Measured stress dependent drained Young's modulus $E_{z}$ perpendicular and $E_{h}$ parallel to the bedding plane, compared with a fitted parameter set (Sec. 5). $S$ and dotted lines indicate the standard deviation of the regression. 


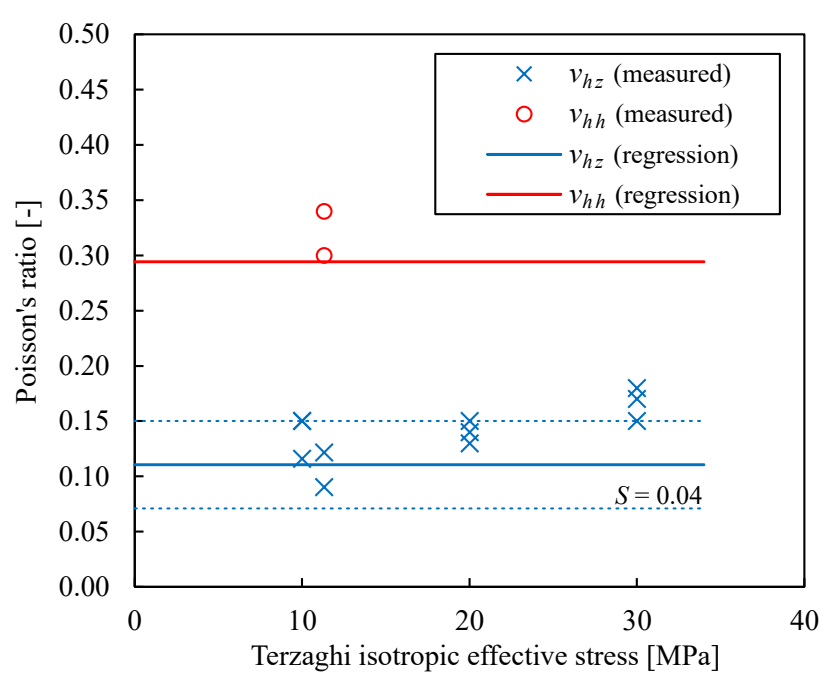

Fig. 19 Measured drained Poisson's ratio $\nu_{z h}$ perpendicular and $\nu_{h h}$ parallel to the bedding planes with respect to effective stress, compared with a fitted parameter set (Sec. 51. $S$ and dotted lines indicate the standard deviation of the regression.

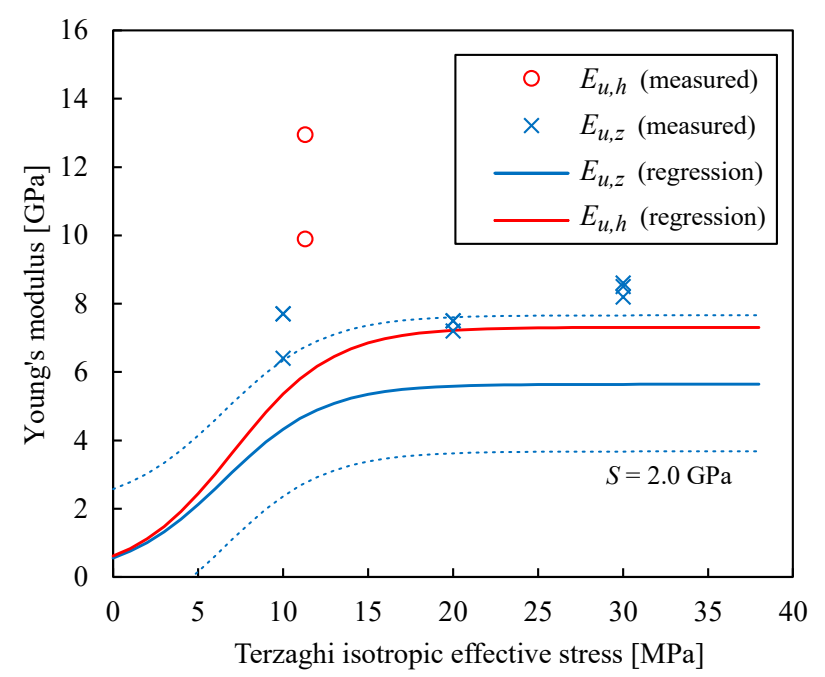

Fig. 20 Measured stress dependent undrained Young's modulus $E_{u, z}$ perpendicular and $E_{u, h}$ parallel to the bedding plane, compared with a fitted parameter set (Sec. 5. $S$ and dotted lines indicate the standard deviation of the regression.

\section{Regression analysis}

The experimental results evidence an increase of the moduli $K_{d}, D_{i}, H, H_{i}$ and $E_{i}$ with increasing Terzaghi effective stress, starting from a certain value at zero effective stress and reaching a plateau at a given effective stress (e.g. Fig. 11). To describe this trend, we chose an empirical, sigmoid function, used regularly in rock mechanics literature (e.g. Zimmerman, 1991, Hassanzadegan et al. 2014, Ghabezloo, 2015). Here we attribute

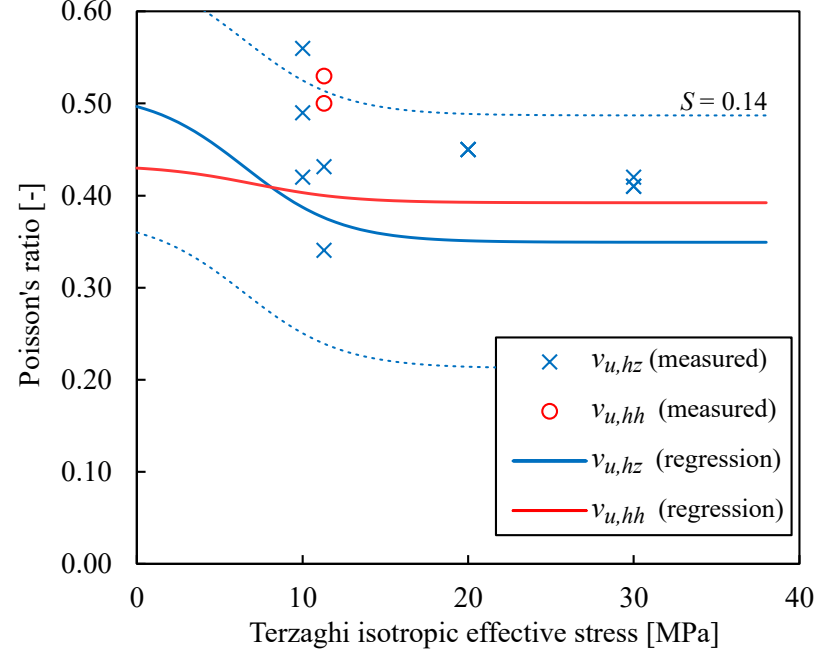

Fig. 21 Measured undrained Poisson's ratio $\nu_{u, z h}$ perpendicular and $\nu_{u, h h}$ parallel to the bedding planes with respect to effective stress, compared with a fitted parameter set (Sec. 5. $S$ and dotted lines indicate the standard deviation of the regression.

the sigmoid function to $E_{z}$ :

$\frac{1}{E_{z}}=\frac{1}{E_{z}^{\infty}}+\left(\frac{1}{E_{z}^{0}}-\frac{1}{E_{z}^{\infty}}\right) \exp \left(-\beta \sigma^{\prime}\right)$

where $E_{z}$ increases with the Terzaghi isotropic effective stress $\sigma^{\prime}$ from a lower limit $E_{z}^{0}$ to an upper limit $E_{z}^{\infty}$, with the shape of transition governed by a parameter $\beta$. In addition, we introduce an anisotropy ratio $R_{E}$, which allows us to calculate $E_{h}$ :

$R_{E}=E_{h} / E_{z}$

Knowing $\nu_{h z}$ and $\nu_{h h}$, the parameters $K_{d}$ and $D_{i}$ can then be evaluated using Eq. (32) and (29). With Eq. 23), one obtains $H$ by inserting the unjacketed compression modulus $K_{s}$. We use then the ratio $R_{H}$ as another fitting parameter, which provides us $H_{i}$ (Eq. (23)). The Biot coefficients $b_{i}$ can now be calculated with Eq. (33) and (34) and the elastic stiffness matrix $M_{i j}$ by Eq. (5) - (9).

To evaluate $M$, one can insert Eq. (37) in Eq. (15), which eliminates $K_{f}$ and $K_{\phi}$ and requires only one additional fitting parameter $K_{u}$ :

$$
\begin{array}{r}
\frac{1}{M}=2\left(1-b_{h}\right)\left(\frac{b_{h}\left(1-\nu_{h h}\right)}{E_{h}}-\frac{b_{z} \nu_{h z}}{E_{z}}\right)+ \\
\frac{\left(1-b_{z}\right)\left(b_{z}-2 b_{h} \nu_{h z}\right)}{E_{z}}+\frac{\left(\frac{1}{K_{d}}-\frac{1}{K_{s}}\right)\left(\frac{1}{K_{u}}-\frac{1}{K_{s}}\right)}{\frac{1}{K_{d}}-\frac{1}{K_{u}}}
\end{array}
$$

In addition, the properties $U_{i}$ (Eq. (31)), the undrained elastic stiffness matrix $M_{i j}^{u}$ (Eq. 201), its inverse $C_{i j}^{u}$, and the parameters $E_{u, i}$ and $\nu_{u, i}$ (Eq. (21)) 
can be determined. We obtain hence a complete set of parameters depending on the nine unknowns $E_{z}^{0}, E_{z}^{\infty}$, $\beta, R_{E}, \nu_{h z}, \nu_{h h}, R_{H}, K_{s}$ and $K_{u}$. Here we assume a priori that the coefficients $R_{E}, R_{H}, \nu_{h z}, \nu_{h h}, K_{s}$ and $K_{u}$ are constant with $\sigma^{\prime}$. Based on these nine coefficients, we can evaluate the theoretical values of the 14 parameters which were investigated in the experiments $\left(D_{i}, H_{i}, U_{i}, E_{i}, \nu_{i}, E_{u, i}\right.$ and $\left.\nu_{u, i}\right)$ and compare them to the measured data.

For a given set of nine unknown coefficients, we can compute the sum of the squared relative errors between all our measured data and the calculated dataset. Due to the fact that different parameters with different units were fitted here, we used the method of squared relative errors. To minimize the sum of residuals we used a Python SciPy differential evolution algorithm (Storn and Price, 1997; Virtanen et al., 2020), which found a global minimum with the values for the nine unknowns presented in Tab. 3. The result of the fitting is displayed together with the experimental data in the respective Figures 11, 12 and 14- 21. For each curve obtained by the regression, we show its standard deviation $S$ in the Figures.

The data on $K_{d}$ and $H$ (Fig. 11,12 show a good fit, with low values of standard deviation $(0.3$ and $0.4 \mathrm{GPa}$, respectively). Here the fit gives a high confidence due to the largest number of experimental data. Moreover, the a priori assumption of constant $K_{s}$ appeared sufficient for reproducing the relationship between the two parameters $K_{d}$ and $H$ (Eq. (23)). The obtained value of $K_{s}=19.69 \mathrm{GPa}$ is very close to the data provided by Belmokhtar et al. (2017b) of $K_{s} \approx 21 \mathrm{GPa}$. In the case of $K_{u}$, we adopted a constant parameter, shown in Fig. 14. Note that due to some significant outliers in the experimental data, the fitted value $K_{u}=10.43$ GPa shows a high standard deviation of $S=3.4$ GPa. Moreover, the fact that the experimental data are not symmetrically distributed around the fitted function indicates a fairly poor fit.

The standard deviation $S$ of the regression for $D_{h}$, $D_{z}, H_{h}$ and $H_{z}$ (Fig. 15 , 16 was found equal to 2.0, $0.5,2.5$ and $0.6 \mathrm{GPa}$, respectively. These values indicate acceptable fitting. For the parameters in $h$ direction, $S$ is generally higher due to the higher absolute values. For $U_{h}$ and $U_{z}$, the values of $S$ were notably higher ( $S=15.5 \mathrm{GPa}$ and $6.7 \mathrm{GPa}$, respectively), due to the high dispersion of the undrained measurements (Fig. 17).

One can see that the fitted relationships for the deviatoric parameters $E_{i}$ and $\nu_{i}$ (Fig. 18, 19) simulate qualitatively the measured anisotropic and stress dependent characteristics of the COx claystone. However, quantitatively we observe a significant underestimation of the measured data, resulting in very large standard deviations $S$ of $E_{z}$ and $\nu_{h z}$ with values of $3.0 \mathrm{GPa}$ and 0.04 , respectively. These large standard deviations are also due to the relatively small number of measurements under triaxial stress conditions. For $E_{h}$ and $\nu_{h h}$, the number of measurements is not sufficient to calculate the standard deviation of the estimate.

Also the obtained relationship for $E_{u, z}$ shows a large standard deviation $S=1.5 \mathrm{GPa}$ (Fig. 20). In parallel bedding direction, we measured a much larger $E_{u, h}$ which is cannot be reproduced by the regression. In this direction, the number of measurements is not sufficient for calculating the standard deviation, but we can observe a poor fit in the Figure. In the experiments we measured relatively high undrained Poisson ratios, larger than 0.35 (Fig. 21). Remarkably, the results of the fitted parameter set show similar values, indicating that these high values are compatible with the poroelastic framework. However, the standard deviation of these regressions is rather high $\left(S=0.14\right.$ for $\nu_{u, h z}$, no quantitative measure for $\nu_{u, h h}$ due to lack of data-points).

\section{Discussion}

The proposed multivariate regression scheme is a useful tool to fit multiple dependent variables (experimental material parameters) through multiple independent variables (model parameters) and to analyse a complex set of transversely isotropic poroelastic parameters. For properties measured under isotropic loading conditions, the model shows a good fit due to the large number of experimental data. Some compatibility issues were encountered in the response to deviatoric loads, where the model significantly underestimates the measured moduli $E_{i}$ and $E_{u, i}$. This could be due to the fact that we express the moduli only as a function of effective isotropic stress, which is not sufficient for reproducing the observed behaviour in deviatoric tests. Some studies (e.g. Cariou et al., 2012, Zhang et al., 2019) reported an increase of the Young modulus as a function of $q$ during tests under partially saturated conditions. Additional experimental results and the consideration of a parameter dependency on $q$ could improve the set of material coefficients.

We are also able to evaluate several other poroelastic characteristics, not measured experimentally, by using the fitted dataset. For instance, we can calculate the Biot modulus $M$ through Eq. (40), presented in Fig. 22 and Tab. 3. This coefficient, often used as a model parameter in engineering applications, changes very little with effective stress and is close to the undrained bulk modulus $K_{u}$. 
Table 3 Summary of the best-fit parameter set. The independent variables were varied in the fitting procedure. We also present values of other resulting parameters with their stress dependency, which are useful for common numerical applications.

\begin{tabular}{|c|c|c|c|c|}
\hline & & Fit & Resulting parameters in function of $\sigma^{\prime}[\mathrm{MPa}]$ & \\
\hline$E_{z}^{0}$ & {$[\mathrm{GPa}]$} & 0.30 & & \\
\hline$E_{z}^{\infty}$ & {$[\mathrm{GPa}]$} & 3.68 & & \\
\hline$\beta$ & {$\left[\mathrm{MPa}^{-1}\right]$} & 0.34 & & \\
\hline$E_{z}$ & {$[\mathrm{GPa}]$} & & {$\left[3.06 \exp \left(-0.34 \sigma^{\prime}\right)+0.27\right]^{-1}$} & [Eq. 38$)]$ \\
\hline$R_{E}$ & {$[-]$} & 1.84 & & \\
\hline$E_{h}$ & {$[\mathrm{GPa}]$} & & $1.84\left[3.06 \exp \left(-0.34 \sigma^{\prime}\right)+0.27\right]^{-1}$ & [Eq. $\cdot 39]$ \\
\hline$\nu_{z h}$ & {$[-]$} & 0.11 & & \\
\hline$\nu_{h h}$ & {$[-]$} & 0.29 & & \\
\hline$R_{H}$ & {$[-]$} & 2.95 & & \\
\hline$K_{s}$ & {$[\mathrm{GPa}]$} & 19.69 & & \\
\hline$b_{h}$ & {$[-]$} & & {$\left[\exp \left(0.34 \sigma^{\prime}\right)+13.02\right] \cdot\left[1.18 \exp \left(0.34 \sigma^{\prime}\right)+13.22\right]^{-1}$} & [Eq. 33] \\
\hline$b_{z}$ & {$[-]$} & & {$\left[\exp \left(0.34 \sigma^{\prime}\right)+13.07\right] \cdot\left[1.14 \exp \left(0.34 \sigma^{\prime}\right)+12.93\right]^{-1}$} & [Eq. $\cdot \overline{\overline{34}}]$ \\
\hline$K_{u}$ & {$[\mathrm{GPa}]$} & 10.43 & & \\
\hline$M$ & {$[\mathrm{GPa}]$} & & $\begin{array}{l}{\left[10.38 \exp \left(1.02 \sigma^{\prime}\right)+2.77 \cdot 10^{2} \exp \left(0.68 \sigma^{\prime}\right)+1.79 \cdot 10^{3} \exp \left(0.34 \sigma^{\prime}\right)\right]} \\
\times\left[\exp \left(1.02 \sigma^{\prime}\right)+0.26 \cdot 10^{2} \exp \left(0.68 \sigma^{\prime}\right)+1.71 \cdot 10^{2} \exp \left(0.34 \sigma^{\prime}\right)-1.89\right]^{-1}\end{array}$ & [Eq.40] \\
\hline
\end{tabular}

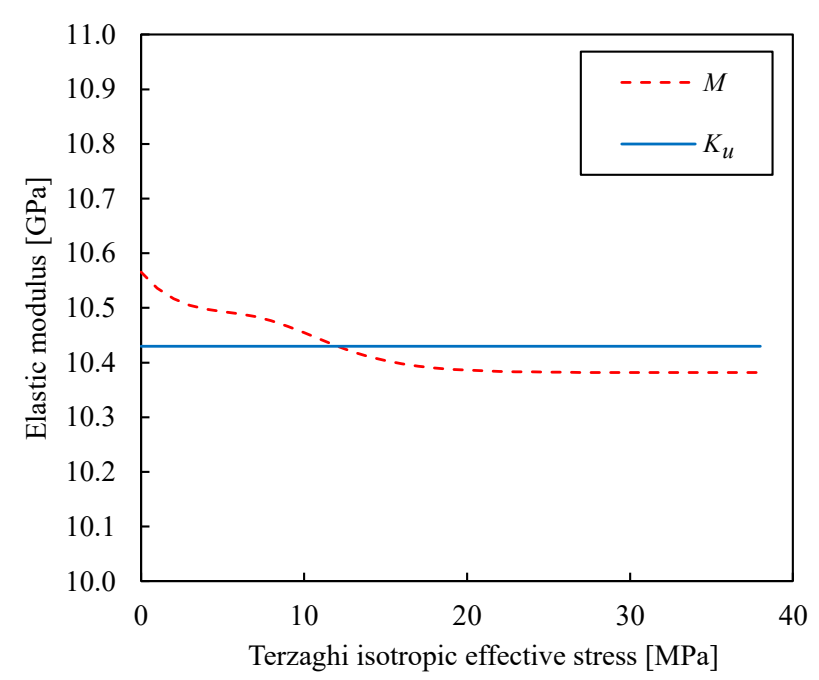

Fig. 22 Biot's modulus $M$ compared with the undrained bulk modulus $K_{u}$, both evaluated through the regression analysis.

The Biot coefficients $b_{h}$ and $b_{z}$ were calculated using Eq. (33) and (34). One can compute stress dependent Biot's coefficients, presented in Fig. 23 and Tab. 3. Both coefficients show values close to 1.0 for low effective stress, decrease slightly with effective stress and remain constant above around $14 \mathrm{MPa}$ effective stress. At the in-situ effective stress of around $10 \mathrm{MPa}$, we obtain values $b_{i}$ close to 0.9 , which is agreement with previous studies (Fig. 23). Interestingly, a less pronounced anisotropy can be seen here, compared to other elastic coefficients. High values of $b_{i}$ originate from small differences between $K_{d}$ and $H$, while a small anisotropy is due to small differences between $D_{h}$ and $H_{h}$, and between $D_{z}$ and $H_{z}$.

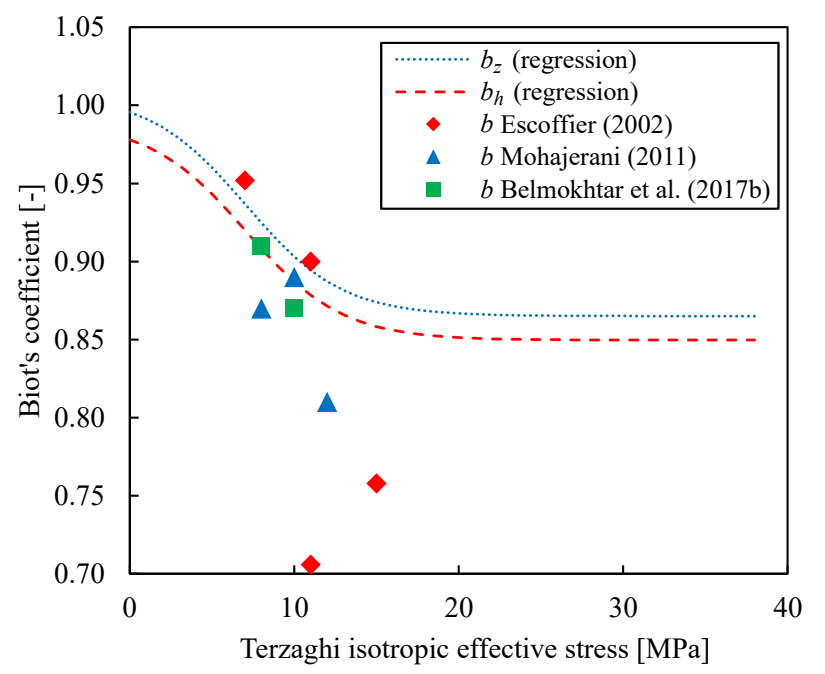

Fig. 23 Biot's effective stress coefficients $b_{i}$ obtained through the regression, compared with literature data on the isotropic parameter $b$. Two datapoints from Escoffier (2002) for $b=0.54$ and 0.32 , both at $23 \mathrm{MPa}$ effective stress, are not shown in the figure.

The isotropic Skempton coefficient $B$ (Fig. 24, calculated through Eq. (35), shows relatively high values between 0.9 and 1.0. Similar to $b_{i}$, this coefficient decreases slightly with effective stress up to $14 \mathrm{MPa}$. Also Belmokhtar et al. (2017b) and Mohajerani et al. (2012, 2014) determined rather high coefficients $B$ with values of 0.87 and 0.84 , respectively. Using Eq. 36, one is able to calculate the 
anisotropic Skempton's coefficients, presented in Fig. 24. Note that here, as well as for $b_{i}$, a combination of different involved regressions increases the uncertainty of the calculated relationships. One observes a large difference between $B_{z}$ and $B_{h}$, with values of 1.6 and 0.5 , respectively, at $10 \mathrm{MPa}$ Terzaghi effective stress. Such significant anisotropies of the Skempton coefficient have been addressed by Holt et al. (2018), who tested soft shales with $B$ close to 1.0. They found properties equivalent to $B_{z}$ around 1.5 and $B_{h}$ around 0.6, similar to the findings of this study. These authors were able to back-calculate their measurements by adopting a transversely isotropic poroelastic model. Moreover, they emphasized the significance of anisotropic $B_{i}$ on pore pressure increase due to subsurface drilling, injection or depletion. In the numerical study of Guayacán-Carrillo et al. (2017), transversely isotropic material parameters provided the best results to model the in-situ measurements of induced pore pressures during excavation of galleries in the COx claystone. Although not discussed explicitly, the material properties used in their study most likely resulted in anisotropic Skempton's parameters, able to reproduce the non-uniform pore pressure field observed around the galleries.

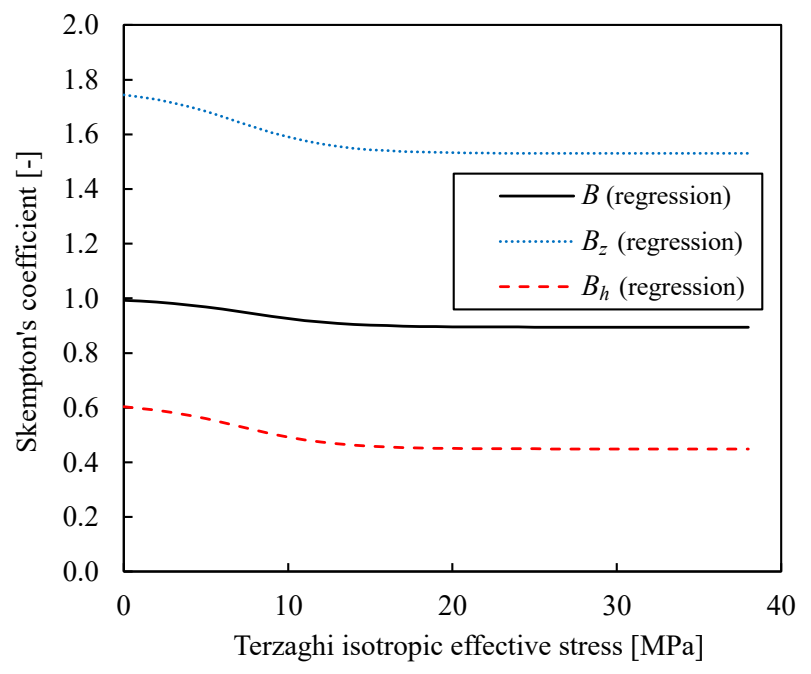

Fig. 24 Skempton's coefficients $B$ and $B_{i}$ evaluated through our regression analysis.

\section{Conclusion}

A laboratory study using experimental equipment and testing procedures adopted for very low permeability materials allowed us to conduct a series of time efficient isotropic and deviatoric experiments on the COx clay- stone. Precise strain gage measurements were employed to investigate its transversely isotropic poromechanical properties and to establish a set of independent poroelastic parameters.

- Tests on different specimens from three cores provided consistent poromechanical coefficients, which confirms the reproducibility of the experiments, the same specimen qualities and shows no noticeable natural variability between the cores.

- The measurements show a clear stress dependency of the drained bulk modulus $K_{d}$ and the Biot modulus $H$, the drained and undrained Young moduli and a less pronounced stress dependency of the undrained bulk modulus and the undrained Young modulus. The drained and undrained Poisson ratios perpendicular to the isotropy plane were observed to change very little with effective stress.

- The decrease of the drained bulk modulus with decreasing effective stress was observed to be reversible in isotropic tests. The reduction of moduli could probably be attributed to an elastic opening of microcracks.

- A remarkable anisotropy was found for several elastic coefficients. The drained Young moduli showed a anisotropy ratio close to 1.8 , while the isotropic stress parameters $D_{i}$ and $H_{i}$ had a ratio close to 3.0 (ratio between modulus parallel and perpendicular to bedding). Drained Poisson's ratios were close to 0.3 parallel to bedding, whereas perpendicular to bedding we found values around 0.15 . In undrained conditions, the anisotropy of moduli was less developed. Relatively high undrained Poisson's ratios around 0.4 illustrate peculiar undrained characteristics.

- We carried out a regression analysis, which aimed to match a stress dependent set of transversely isotropic poroelastic coefficients to the laboratory measurements. The obtained seven independent coefficients (9 coefficients due to stress dependency, Tab. 3) could satisfactorily represent the measured parameters under isotropic loading conditions. Some compatibility issues were encountered, where elastic properties evaluated from deviatoric tests tend to be stiffer than those back-calculated from the fitted parameter set.

- The observed poor fit for parameters measured under deviatoric loading conditions could be improved by additional experimental data, by taking into account a parameter dependency on deviatoric stress or considering other effects, which are not captured by our transversely isotropic poroelasticity assumption with parameters depending on isotropic stress only. 
- The fitted unjacketed compression modulus, which is assumed to be isotropic at the micro-scale and constant with effective confining stress, gave a value of $K_{s}=19.69 \mathrm{GPa}$. This is in accordance with the direct measurements of Belmokhtar et al. (2017b).

- A negligible anisotropy of the calculated Biot's coefficients $b_{h}$ and $b_{z}$ was indicated by the fitted parameters. Relatively high values of the Biot coefficients highlight the importance of hydromechanical couplings in this material. The calculated Skempton's coefficients showed a significant anisotropy, with higher values perpendicular to bedding.

The precise knowledge of the poromechanical properties of the COx claystone is important not only for the hydromechanical modelling of the rock behaviour around excavated drifts (Guayacán-Carrillo et al., 2017), but also for the analysis of the deformations due to thermally induced pore pressures (Gens et al. 2007; Garitte et al., 2017). The parameters evaluated in this study give confidence due to their intercompatibility, evidencing a clear anisotropy. The observed stress dependency of elastic properties could be considered in in-situ modelling. The material was seen to become more compliant under decreasing effective stresses, which increases the elastic deformations in unloading paths.

\section{Conflict of interest}

The authors declare that there are no known conflicts of interest associated with this publication.

\section{References}

Aichi M, Tokunaga T (2012) Material coefficients of multiphase thermoporoelasticity for anisotropic micro-heterogeneous porous media. International Journal of Solids and Structures 49(23-24):3388-3396

Andra (2005) Dossier 2005 Argile: Evaluation of the feasibility of a geological repository in an argillaceous formation. URL https://international.andra.fr/sites/international/ files/2019-03/3- Dossier 2005 Argile Synthesis - Evaluation of the feasibility of a geological repository in an argillaceous formation_0.pdf

Belmokhtar M, Delage P, Ghabezloo S, Conil N (2017a) Thermal Volume Changes and Creep in the CallovoOxfordian Claystone. Rock Mechanics and Rock Engineering 50(9):2297-2309

Belmokhtar M, Delage P, Ghabezloo S, Tang AM, Menaceur H, Conil N (2017b) Poroelasticity of the
Callovo-Oxfordian Claystone. Rock Mechanics and Rock Engineering 50(4):871-889

Belmokhtar M, Delage P, Ghabezloo S, Conil N (2018) Drained Triaxial Tests in Low-Permeability Shales: Application to the Callovo-Oxfordian Claystone. Rock Mechanics and Rock Engineering 51(7):1979 1993

Berryman JG (1992) Effective stress for transport properties of inhomogeneous porous rock. Journal of Geophysical Research 97(B12):17409-17424

Biot MA, Willis DG (1957) The Elastic Coefficients of the Theory of Consolidation. Journal of Applied Mechanics 24:594-601

Braun P, Ghabezloo S, Delage P, Sulem J, Conil N (2019) Determination of Multiple Thermo-HydroMechanical Rock Properties in a Single Transient Experiment: Application to Shales. Rock Mechanics and Rock Engineering 52(7):2023-2038

Braun P, Ghabezloo S, Delage P, Sulem J, Conil N (2020) Thermo-poro-elastic behaviour of a transversely isotropic shale: Thermal expansion and pressurization. Rock Mechanics and Rock Engineering p 1-17, DOI 10.1007/s00603-020-02269-y

Brown RJS, Korringa J (1975) On the dependence of the elastic properties of a porous rock on the compressibility of the pore fluid. Geophysics 40(4):608616

Cariou S, Duan Z, Davy C, Skoczylas F, Dormieux L (2012) Poromechanics of partially saturated COx argillite. Applied Clay Science 56:36-47

Cheng AHD (1997) Material coefficients of anisotropic poroelasticity. International Journal of Rock Mechanics and Mining Sciences 34(2):199-205

Chiarelli AS (2000) Étude expérimentale et modélisation du comportement mécanique de l'argilite de l'Est, Influence de la profondeur et de la teneur en eau. PhD thesis, Université Lille I

Conil N, Talandier J, Djizanne H, de La Vaissière R, Righini-Waz C, Auvray C, Morlot C, Armand G (2018) How rock samples can be representative of in situ condition: A case study of Callovo-Oxfordian claystones. Journal of Rock Mechanics and Geotechnical Engineering 10(4):613-623

Coussy O (2004) Poromechanics. J. Wiley \& Sons, New York

Escoffier S (2002) Caractérisation expérimentale du comportement hydroméchanique des argilites de Meuse/Haute-Marne. PhD thesis, Institut National Polytechnique de Lorraine

Ewy RT (2015) Shale/claystone response to air and liquid exposure, and implications for handling, sampling and testing. International Journal of Rock Mechanics and Mining Sciences 80:388-401 
Favero V, Ferrari A, Laloui L (2018) Anisotropic Behaviour of Opalinus Clay Through Consolidated and Drained Triaxial Testing in Saturated Conditions. Rock Mechanics and Rock Engineering 51(5):13051319

Fortin J, Schubnel A, Guéguen Y (2005) Elastic wave velocities and permeability evolution during compaction of bleurswiller sandstone. International Journal of Rock Mechanics and Mining Sciences 42(7):873 $-889$

Garitte B, Nguyen TS, Barnichon JD, Graupner BJ, Lee C, Maekawa K, Manepally C, Ofoegbu G, Dasgupta B, Fedors R, Pan PZ, Feng XT, Rutqvist J, Chen F, Birkholzer J, Wang Q, Kolditz O, Shao H (2017) Modelling the Mont Terri HE-D experiment for the Thermal-Hydraulic-Mechanical response of a bedded argillaceous formation to heating. Environmental Earth Sciences 76(9):1-20

Gassmann F (1951) Über die Elastizität poröser Medien. Vierteljahrsschrift der Naturforschenden Gesellschaft in Zürich 96(1-51):1-21

Gens A, Vaunat J, Garitte B, Wileveau Y (2007) In situ behaviour of a stiff layered clay subject to thermal loading: observations and interpretation. Géotechnique 57(2):207-228

Gercek H (2007) Poisson's ratio values for rocks. International Journal of Rock Mechanics and Mining Sciences 44(1):1-13, DOI 10.1016/j.ijrmms.2006.04.011

Ghabezloo S (2015) A micromechanical model for the effective compressibility of sandstones. European Journal of Mechanics - A/Solids 51:140-153

Ghabezloo S, Sulem J, Guédon S, Martineau F, SaintMarc J (2008) Poromechanical behaviour of hardened cement paste under isotropic loading. Cement and Concrete Research 38:1424-1437

Guayacán-Carrillo LM, Ghabezloo S, Sulem J, Seyedi DM, Armand G (2017) Effect of anisotropy and hydro-mechanical couplings on pore pressure evolution during tunnel excavation in low-permeability ground. International Journal of Rock Mechanics and Mining Sciences 97:1-14

Hart DJ, Wang HF (2001) A single test method for determination of poroelastic constants and flow parameters in rocks with low hydraulic conductivities. International Journal of Rock Mechanics and Mining Sciences 38(4):577-583

Hassanzadegan A, Blöcher G, Milsch H, Urpi L, Zimmermann G (2014) The effects of temperature and pressure on the porosity evolution of flechtinger sandstone. Rock Mechanics and Rock Engineering 47(2):421-434

Hatheway AW, Kiersch GA (1982) Engineering properties of rock. In: Carmichael RS (ed) Handbook of
Physical Properties of Rocks, CRC Press, Boca Raton FL, pp 289-331

Holt RM, Bakk A, Stenebraten JF, Bauer A, Fjaer E (2018) Skempton's A - A key to man-induced subsurface pore pressure changes. In: 52nd U.S. Rock Mechanics/Geomechanics Symposium, American Rock Mechanics Association, Seattle

Islam MA, Skalle P (2013) An experimental investigation of shale mechanical properties through drained and undrained test mechanisms. Rock Mechanics and Rock Engineering 46(6):1391-1413

Makhnenko RY, Tarokh A, Podladchikov YY (2017) On the Unjacketed Moduli of Sedimentary Rock. In: Vandamme M, Dangla P, Pereira JM, Ghabezloo S (eds) Poromechanics VI - Proceedings of the 6th Biot Conference on Poromechanics, American Society of Civil Engineers, pp 897-904

Menaceur H, Delage P, Tang Am, Conil N (2015) The thermo-mechanical behaviour of the CallovoOxfordian claystone. International Journal of Rock Mechanics and Mining Sciences 78:290-303

Mohajerani M (2011) Etude experimentale du comportement thermo-hydro-mecanique de l'argilite du Callovo-Oxfordien. PhD thesis, Université Paris-Est Mohajerani M, Delage P, Sulem J, Monfared M, Tang AM, Gatmiri B (2012) A laboratory investigation of thermally induced pore pressures in the CallovoOxfordian claystone. International Journal of Rock Mechanics and Mining Sciences 52:112-121

Mohajerani M, Delage P, Sulem J, Monfared M, Tang AM, Gatmiri B (2014) The thermal volume changes of the Callovo-Oxfordian claystone. Rock Mechanics and Rock Engineering 47(1):131-142

Popov VL, Heß M, Willert E (2019) Transversely Isotropic Problems, Springer Berlin Heidelberg, Berlin, Heidelberg, pp 205-212

Rad NS, Clough GW (1984) New procedure for saturating sand specimens. Journal of Geotechnical Engineering 110(9):1205-1218

Schmitt L, Forsans T, Santarelli F (1994) Shale testing and capillary phenomena. International Journal of Rock Mechanics and Mining Sciences \& Geomechanics Abstracts 31(5):411 - 427

Skempton AW (1954) The Pore-Pressure Coefficients A and B. Géotechnique 4(4):143-147

Storn R, Price K (1997) Differential evolution-a simple and efficient heuristic for global optimization over continuous spaces. Journal of global optimization 11(4):341-359

Tang AM, Cui YJ, Barnel N (2008) Thermomechanical behaviour of a compacted swelling clay. Géotechnique 58(1):45-54 
Ting TC, Chen T (2005) Poisson's ratio for anisotropic elastic materials can have no bounds. Quarterly Journal of Mechanics and Applied Mathematics 58(1):7382

Virtanen P, Gommers R, Oliphant TE, Haberland M, Reddy T, Cournapeau D, Burovski E, Peterson P, Weckesser W, Bright J, van der Walt SJ, Brett M, Wilson J, Jarrod Millman K, Mayorov N, Nelson ARJ, Jones E, Kern R, Larson E, Carey C, Polat I, Feng Y, Moore EW, VanderPlas J, Laxalde D, Perktold J, Cimrman R, Henriksen I, Quintero EA, Harris CR, Archibald AM, Ribeiro AH, Pedregosa F, van Mulbregt P, and SciPy 1.0 Contributors (2020) SciPy 1.0: Fundamental Algorithms for Scientific Computing in Python. Nature Methods 17:261-272, DOI https://doi.org/10.1038/s41592-019-0686-2, (in press)

Vutukuri VS, Lama RD, Saluja SS (1974) Handbook on mechanical properties of rocks. Trans Tech Publications, Clausthal

Wileveau Y, Cornet FH, Desroches J, Blumling P (2007) Complete in situ stress determination in an argillite sedimentary formation. Physics and Chemistry of the Earth 32(8-14):866-878

Zhang CL, Armand G, Conil N, Laurich B (2019) Investigation on anisotropy of mechanical properties of Callovo-Oxfordian claystone. Engineering Geology 251:128-145

Zhang F, Xie SY, Hu DW, Shao JF, Gatmiri B (2012) Effect of water content and structural anisotropy on mechanical property of claystone. Applied Clay Science 69:79-86

Zimmerman RW (1991) Compressibility of sandstones. Elsevier Sci., Amsterdam

Zimmerman W, Somerton WH, King MS (1986) Compressibility of Porous Rocks. Journal of Geophysical Research 91(B12):12765-12777 